\title{
Repair mechanisms in embryos: wound healing and learning from how embryos repair perfectly
}

\author{
P. Martin
}

\begin{abstract}
Embryos heal wounds very rapidly and efficiently without leaving a scar. Studying how they do this can tell a great deal about the natural morphogenetic movements of embryogenesis as well as suggesting ways in which adult tissues could repair more efficiently. Using live confocal imaging of transgenic Drosophila embryos expressing green fluorescent protein-labelled actin in epithelial tissues, the key actin machineries that drive the paradigm morphogenetic process of dorsal closure, which appear to bear striking analogy with re-epithelialisation of a vertebrate skin wound have been revealed. Using embryos expressing mutant forms of the various small guanadine triphosphatases, the function of each of these actin-based elements, the actin cable and dynamic filopodia and lamellipodia, were tested in both dorsal closure and the repair of laser-generated wound holes in the fly embryo. These experiments conducted in embryonic chicks and mice and in the neonatal PU.1 null mouse, which is genetically macrophageless, suggest that an inflammatory
\end{abstract}

response is not essential for healing and may indeed be causal of fibrosis in postembryonic animals. Consequently, a microarray approach was used with this mouse in order to identify a portfolio of candidate inflammation/fibrosis genes. Finally, by taking advantage of the translucency of the zebrafish larval tail, the author's group has begun to make differential interference contrast movies of the inflammatory response and to dissect the genetics of this process by screening for mutants that fail to recruit leukocytes to the wound site and by morpholino knockdown of candidate "inflammation" genes. The hope is that these basic cell and molecular studies in genetically tractable organisms will supply the clues needed to design the new repair and regeneration medicines of the future.

Correspondence: P. Martin, Dept of Anatomy and Development Biology, University College London, Gower Street, London WC1E 6BT, UK. Fax: 44 2076797349. E-mail: paul.martin@ucl.ac.uk

\section{Abstracts}

Nitric oxide inhibits IKK through S-nitrosation and S-glutathiolation and prevents activation of $N F-\kappa B$

Nitric oxide (NO) possesses anti-inflammatory effects, which may be exerted via its ability to inhibit the nuclear factor (NF)-КB via $S$-nitrosation of cysteine 62 of the p50 subunit. In the present study, it was assessed whether NO could also inhibit NF- $\kappa$ B by preventing the activation of I $\kappa B$ kinase (IKK), the enzyme complex necessary for $N F-\kappa B$ activation.

Mouse lung epithelial cells (C10 cells) were exposed to tumour necrosis factor (TNF) in the presence or absence of the $S$-nitrosothiols $S$-nitroso- $N$-acetylpenicillamine (SNAP) or $S$-nitrosoglutathione (GSNO) for evaluation of IKK enzymatic activity. The addition of GSNO to intact cells inhibited TNF-induced IKK activity, whereas SNAP inhibited IKK only when glutathione (GSH) was depleted. In contrast, addition of $100 \mu \mathrm{M}-1 \mathrm{mM}$ SNAP or GSNO to isolated active IKK, from cells with a normal GSH content, resulted in a dose-dependent inhibition of enzymatic activity. Assessment of $S$-nitrosation by biotinylation and Western blotting revealed that the IKK- $\beta$ subunit became $S$-nitrosated following exposure to SNAP and GSNO. GSH was also found to inhibit IKK activity, but was less effective than GSNO. Immunoprecipitation and Western blotting showed that GSH and GSNO glutathiolate IKK- $\beta$.

When $\mathrm{C} 10$ cells were incubated with $1 \mathrm{mM} \mathrm{N}$-monomethylL-arginine to inhibit all three NO synthase enzymes IKK activity was not induced, whereas $\mathrm{NF}-\kappa \mathrm{B}$-dependent reporter gene expression did increase. NFאB DNA binding and reporter gene expression were inhibited following the addition of GSNO, GSH and SNAP, independent of the GSH content of the cells. These data demonstrate that oxidative inactivation of IKK is a mode to downregulate $N F-\kappa B$ in response to $\mathrm{NO}$.

N.L. Reynaert*, K. Ckless*, A. van der Vliet*, S. Korn*, N. Vos*, E.F.M. Wouters", Y. Janssen-Heininger*

*Dept of Pathology, University of Vermont, Burlington, VT, USA. " Dept of Pulmonology, Maastricht University, Maastricht, The Netherlands.

Modulation of human lung dendritic cell recruitment: role of alveolar epithelium

Chronic obstructive pulmonary disease and asthma both display a chronic inflammatory component that is thought to be partly T-cell driven. Studies have shown that dendritic cells (DCs) are elevated in both disorders. It is thought that the inflammatory response of T-cells is initiated by antigenpresenting DCs residing within the mucosa and alveolar septae.

The CC chemokine macrophage inflammatory protein (MIP)-3 $\alpha$ is a specific chemoattractant for DCs, in particular the Langerhans' cell subset that colonise the subepithelia. The authors have shown that primary human alveolar type (HAT)-II cells produce MIP-3 $\alpha$ constitutively and that 
release is increased in response to lipopolysaccharide (LPS) in a time- and dose-dependent manner (fig. 1). Using immunocytochemistry it was also shown that the majority of monocytes in the lung interstitium are CD1a ${ }^{+}$DCs. Monocytes found in washings from the airspace are predominantly $\mathrm{CD}^{+} 8^{+}$i.e. macrophages; very few are $\mathrm{CD} 1 \mathrm{a}^{+}$.

The effect of MIP- $3 \alpha$ on DC migration was investigated by culturing immature DCs derived from peripheral blood monocytes. DCs were added to the upper part of an invasion chamber and varying concentrations of recombinant MIP-3 $\alpha$ to the lower. Migration increased in a dose-dependent manner with a three-fold increase at $6,000 \mathrm{pg} \cdot \mathrm{mL}^{-1}(\mathrm{p}<0.0001)$. In addition the chemotactic capacity of conditioned media from LPS-stimulated HAT II cells $(\mathrm{n}=3)$ was assessed. Conditioned media was collected $24 \mathrm{~h}$ post-LPS and therefore LPS-free. DC migration towards the conditioned media correlated directly with the amount of MIP- $3 \alpha\left(r^{2}=0.94\right)$ but not with other chemokines detected in the media (interleukin-8, monocyte chemotactic protein-1 and growth-related protein- $\alpha$ ). Furthermore,

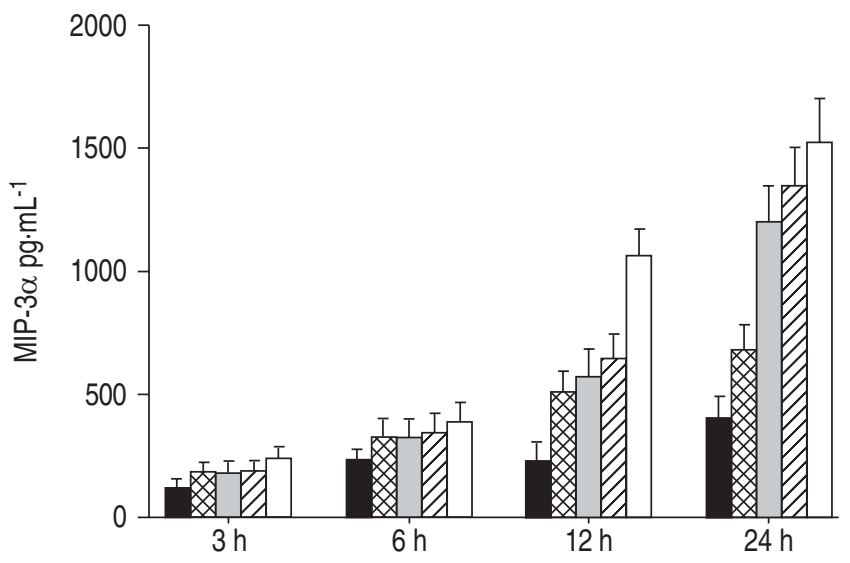

Fig. 1.-Time- and dose-dependent release of macrophage inflammatory protein (MIP)-3 $\alpha$ from primary human alveolar type-II cells in response to lipopolysaccharide (LPS) stimulation $(n=6)$. $\mathbf{\square}$ : control; ‥ $1 \mathrm{ng} \cdot \mathrm{mL}^{-1} \mathrm{LPS} ; \quad: 10 \mathrm{ng} \cdot \mathrm{mL}^{-1} \mathrm{LPS} ; \mathbb{Z}: 100 \mathrm{ng} \cdot \mathrm{mL}^{-1} \mathrm{LPS} ; \square$ : $1000 \mathrm{ng} \cdot \mathrm{mL}^{-1} \mathrm{LPS}$.

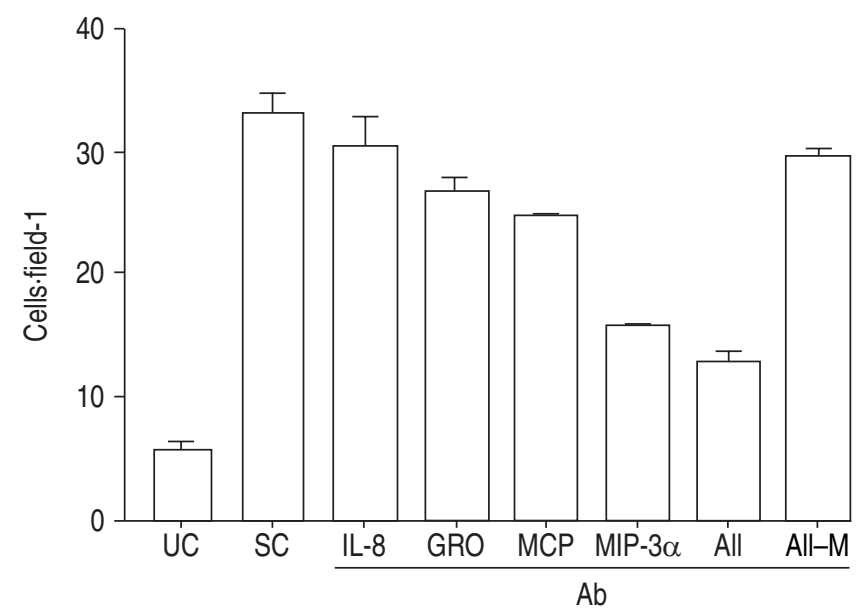

Fig. 2. - Inhibition of dendritic cell migration by antibodies (Ab) to chemokines present in conditioned media from lipopolysaccharidestimulated human alveolar type-II cells $(n=3)$. UC: unstimulated control; SC: stimulated control; IL: interleukin; GRO: growth-related protein; MCP: monocyte chemotactic protein; MIP: macrophage inflammatory protein; All-M: all antibodies except MIP- $\alpha$. using selective chemokine antibodies, blockade of MIP-3 $\alpha$ was shown to cause the greatest inhibition in DC migration (fig. 2).

To conclude, HAT II cells play an important role in regulation of DC recruitment in the lung, most likely via MIP$3 \alpha$ production.

A.J. Thorley*, P. Goldstraw*, A. Young\# , T.D. Tetley* *National Heart and Lung Institute, Imperial College, London, and ${ }^{\#}$ AstraZeneca, Loughborough, UK.

Effects of anti-IL-5 on bone marrow CD34+ eosinophils after allergen exposure: influence on airway eosinophilia

Airway allergen exposure induces enhanced eosinophil (eos) production, and increases the number of circulating CD34+ cells. Interleukin (IL)-5 is an especially important mediator in orchestrating this eosinophilic inflammatory response. The aim was to elucidate the onset of effect of a monoclonal antibody to IL-5 (TRFK5) in reducing eosinophilia induced by airway allergen exposure.

Ovalbumin (OVA)-sensitised Balb/c mice were exposed to OVA $(100 \mu \mathrm{g})$ intranasally on 10 days with 2 days of rest between exposure days 5 and 6 . TRFK $5\left(50 \mu \mathrm{g} \cdot \mathrm{animal}^{-1}\right)$ or its isotype control was given once intraperitoneally before the last 5 days of allergen exposure. Bronchoalveolar lavage (BAL), peripheral blood (PB) and bone marrow (BM) cells were collected at different days after the treatment. Newly produced eos were pulse-labelled with bromodeoxyuridine (BrdU). BrdU-labelled eos and CD34+ eos numbers were examined by immunocytochemistry.

BM eos were significantly reduced on the third day after TRFK 5 administration versus vehicle-treated mice, due to the decrease of immature eos $(3.05 \pm 0.50$ versus $6.08 \pm 0.82 \%$ of total cells, $\mathrm{p}<0.05)$. This effect was further enhanced on the fifth day, as well as on BM BrdU-labelled eos, and CD34+ eos $(1.10 \pm 0.22$ versus $4.13 \pm 0.91 \%$ of total cells, $\mathrm{p}<0.05)$. Similar effects were observed on PB eos counts. However, a significant effect on BAL fluid eos was found only on the fifth day after TRFK5 administration $\left(3.14 \pm 0.99\right.$ versus $62.20 \pm 13.78 \times 10^{4}$. $\left.\mathrm{mL}^{-1}, \mathrm{p}<0.05\right)$. At this time point, there was also a significant inhibitory effect on BrdU-labelled eos $(0.58 \pm 0.39$ versus $15.54 \pm 6.55 \times 10^{4} \cdot \mathrm{mL}^{-1}$ ) as well as on CD34+eos in BAL.

A single dose of anti-IL-5 extensively reduces BM CD34+ eos, immature BM eos and $\mathrm{PB}$ eos, as well as BAL BrdUpositive eos and BAL CD34+ eos numbers. Together these data argue that anti-IL-5, in vivo, is important to an extent to regulate eosinophilia by action within the BM, probably by inhibition of the early maturation of eos from CD34+ progenitor cells.

B. Sitkauskiene*, M. Sjöstrand ${ }^{\#}$, A-K. Johansson ${ }^{\#}$, J. Lötvall ${ }^{\#}$ *Clinic of Pulmonology and Immunology, Kaunas University of Medicine, Lithuania. " Lung Pharmacology Group, Dept of Respiratory Medicine and Allergology, Gothenburg University, Sweden.

Attenuation of IgE-receptor signalling in mast cells as a molecular basis for the antiallergic action of glucocorticoids

Glucocorticoids exhibit anti-inflammatory, immune suppressive and antiallergic activities. They inhibit the release of allergic mediators and the expression of proinflammatory cytokines, processes induced by activation of the receptor with high affinity for immunoglobulin E (FceRI) upon 
antigen trigger in mast cells. The mode(s) of action of glucocorticoids in inhibiting FceRI signalling were analysed. Glucocorticoids suppress the expression of FceRI $\alpha$-chain gene at the promoter level. The downregulation of the FceRI $\alpha$-chain gene expression requires new protein synthesis and regulatory elements at the FceRI $\alpha$-chain promoter and correlates with a reduced surface expression of the FceRI. This downregulation would possibly suppress signal transduction originating from the FceRI and ending up with the activation of the downstream targets, extracellular signalrelated kinase (ERK)1/2.

In addition, glucocorticoids enhance the expression of the mitogen-activated protein kinase phosphatase MKP-1, which inhibits the activation of ERK1/2, at the promoter level. This regulation requires the glucocorticoid receptor dimerisation function and the presence of discrete elements on the promoter proximal sequence. The role of MKP-1 in glucocorticoidmediated repression of ERK1/2 phosphorylation was confirmed in primary bone marrow-derived mast cells from MKP-1deficient mice, where ERK1/2 are no longer inhibited by glucocorticoids, while this is the case in cells from wildtype mice. Instead, ERK1/2 activity in other cell types, such as thymocytes and splenocytes of MKP-1-deficient mice, could still be inhibited by glucocorticoids, demonstrating that repression of ERK1/2 through MKP-1 is a cell-type specific process. Glucocorticoid-mediated inhibition of expression of FceRI $\alpha$ gene and increased expression of MKP-1 may possibly function together in the attenuation of FceRI signalling by glucocorticoids.

\section{A. Sancono*, O. Kassel*, J. Maier*, C. Hesslinger ${ }^{\#}$, A.C.B. Cato* \\ *Forschungszentrum Karlsruhe, Institute of Toxicology and} Genetics, and "Pharmazentrum Frankfurt, Institute for General Pharmacology, Klinikum of the J. W. Goethe University, Frankfurt am Main, Germany.

\section{The presence of quorum-sensing signal molecules in clinically stable lung}

Infection with bacteria such as Pseudomonas is common in lung allograft recipients, particularly during chronic rejection. Analysis of sputum samples from cystic fibrosis patients infected with Pseudomonas aeruginosa or Burkholderia cepacia have indicated the presence of the bacterial $N$-acylhomoserine lactones (AHLs) quorum-sensing signalling molecules. AHLs not only control the expression of bacterial virulence genes but are also involved in stimulating the maturation of antibiotic-resistant biofilms. AHL activity may be detected even in clinically stable lung transplant recipients free of clinical infection or rejection.

A standardised $3 \times 60 \mathrm{~mL}$ bronchoalveolar lavage (BAL) was taken from nine stable, nonsmoking, lung transplant recipients, 3-12 months post-transplant. Detection of AHLs was carried out on dichloromethane-extracted supernatants, using the bioluminescence-based AHL reporter plasmid pSB1075. This responds to AHLs with long acyl chains (10-14 C), generating light. Synthetic AHLs were included as positive controls.

From the nine BAL supernatants, five exhibited AHL activity, suggesting the presence of long-chain AHLs. There was no correlation between the levels of AHLs detected, or their absence, BAL microbiology or pretransplant diagnosis (fig. 1).

These data provide the first evidence of AHL quorumsensing signals in human lung allograft recipients, with activity even in subjects with no rejection or infection. Longitudinal

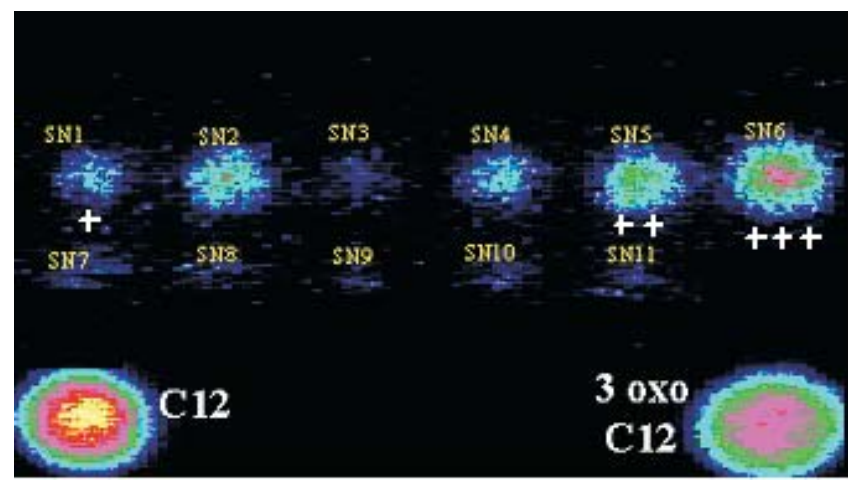

Fig. 1.- Representative bioluminescence photon capture. $\mathrm{C} 12$ and 3 oxo C12: $N$-acylhomoserine lactone (AHL) standards.,,$++++1+$ : levels of AHLs detected.

studies are required of AHL levels, to elucidate potential links with infection, rejection and allograft deterioration.

C Ward*, M. Cámara\#, I. Forrest*, B. Rutherford*, G. Pritchard*, M. Daykin", A. De Soyza*, A. J. Fisher*, P. Williams*, P.A. Corris*'

*University of Newcastle upon Tyne, Newcastle upon Tyne, and ${ }^{\#}$ University of Nottingham, Nottingham, UK.

Rapid expression of acute-phase reactants in lung after local LPS exposure in mice

The respiratory system is continuously exposed to lipopolysaccharide (LPS) due to inhalation of airborne LPS present as contaminant on cigarette smoke, air pollution, organic and house dusts. Expression of acute-phase reactants (APR) at the site of LPS exposure may enhance the early phase of specific local responses to injury and infection before inflammation induces capillary leakage and extravasation of serum APR. The present study aims to investigate pulmonary expression of four major murine APR after local LPS exposure.

Male Swiss mice received intratracheal $5 \mu \mathrm{g}$ LPS (Escherichia coli O55:B5), whereas control mice received saline or no treatment. Mice were sacrificed 4, 8, 24 and $72 \mathrm{~h}$ after LPS exposure. Neutrophil influx in the lungs was determined histologically as a characteristic for airway inflammation. Pulmonary and hepatic expression of serum amyloid $\mathrm{P}$ component (SAP), $\alpha_{1}$-acid glycoprotein (AGP), LPS-binding protein (LBP) and $\alpha_{1}$-antitrypsin $\left(\alpha_{1}-\mathrm{AT}\right)$ were assessed by RT-PCR. In addition, plasma levels of SAP, AGP, LBP, and $\alpha_{1}$-AT were determined by ELISA or Western blotting.

Local LPS exposure induced a strong but transient influx of neutrophils into the airways, peaking at $24 \mathrm{~h}$. Increased pulmonary expression of mRNA for $\alpha_{1}$-AT, AGP and LBP was detected by RT-PCR at $4 \mathrm{~h}$, which was also present at 24 and $72 \mathrm{~h}$ after LPS exposure. Little or no expression of APR was detected in lung tissue of control mice. Although pulmonary expression of SAP mRNA was not induced by LPS exposure, systemic levels of SAP were elevated from $24 \mathrm{~h}$ postexposure. In addition, plasma AGP and LBP were elevated, whereas plasma $\alpha_{1}$-AT remained unchanged. Systemic elevation of APR was found to be associated with increased hepatic expression of mRNA for SAP, AGP and LBP.

Local LPS exposure induces rapid expression of APR in 
the lung, which clearly precedes systemic elevation of APR associated with hepatic APR expression.

J.H.J. Vernooy, N. Reynaert, T.G. Wolfs, B. de Vries, M.A. Dentener, W.A. Buurman, E.F.M. Wouters

Nutrition and Toxicology Research Institute Maastricht (NUTRIM), Depts of Pulmonology and General Surgery, University Hospital Maastricht, Maastricht, The Netherlands.

De novo synthesis of IL-17 in human airways following exposure to organic dust

The cytokine interleukin (IL)-17 is produced by activated T-lymphocytes and may contribute to recruitment and activation of neutrophils in the airways. The aim of this study was to determine whether IL-17 is synthesised de novo during airway inflammation induced by organic dust.

Four healthy nonsmoking volunteers were exposed to organic dust for $3 \mathrm{~h}$ while working in a swine confinement. Bronchoalveolar lavage (BAL) fluid was gathered 2 weeks before and $24 \mathrm{~h}$ after the exposure and IL-17 mRNA was measured using RT-PCR-ELISA. Total and cell differential counts were also performed in BAL fluid.

The exposure to organic dust caused an 11.1-fold increase of IL-17 mRNA levels (\% HPRT; median (range)) from 7.45 $(0-21.9)$ to $82.7(0.35-118.2),(n=4 ; p<0.05)$. In BAL fluid, there was a corresponding increase (before versus after median million cells $\left.\cdot \mathrm{L}^{-1}\right)$ in lymphocytes (3.7 versus 13.15 ) and neutrophils (2.25 versus 15.87$)$.

In conclusion, IL-17 can be synthesised de novo during airway inflammation induced by organic dust. The synthesis of IL-17 is associated with the recruitment of lymphocytes and neutrophils. Further investigations are needed to determine whether IL-17 constitutes a potential target for pharmacotherapy of airway disease characterised by an exaggerated mobilisation of neutrophils.

\section{S. Ivanov*, O. Prause*, L. Palmberg ${ }^{\#}$, K. Larsson ${ }^{\#}$, A. Lindén* \\ *Lung Pharmacology Group, Dept of Respiratory Medicine and Allergology, Gothenburg University, Gothenburg, and

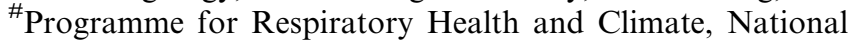 Institute of Environmental Medicine, Karolinska Institute, Stockholm, Sweden.}

Lack of the transcription factor CEBP- $\alpha$ and different intracellular signalling in asthmatic bronchial smooth muscle cells

The pathogenesis of asthma is characterised by increased proliferation of bronchial smooth muscle cells (BSMCs) and enhanced production of proinflammatory cytokines. However, the molecular basis of this disease remains unclear. The authors have previously shown that $\beta$-receptor agonists are capable of activating the glucocorticoid receptor (GR) in BSMCs and in peripheral blood leukocytes. The transcription factor CEBP- $\alpha$ is centrally involved in the steroid activation pathway forming a complex when activated.

The expression and activation of the GR and the transcription factor CEBP- $\alpha$, and the secretion of interleukin (IL)- 6 in BSMCs cultured from asthmatics and nonasthmatic controls were studied. GR and CEBP- $\alpha$ were assessed by electrophoretic mobility shift assay (EMSA) and Western blot. IL-6 was determined by ELISA. In asthmatic BSMCs, the GR was activated by steroids. The glucocorticoid-dependent inhibition of cell proliferation was not significant, while the anti-inflammatory effect shown as downregulation of IL-6 secretion was functioning. In contrast, the antiproliferative effect of $\beta_{2}$-agonists was observed in asthmatic and nonasthmatic BSMCs, as well as an induction of IL-6 secretion. Using Western blot and EMSA, it was shown that asthmatic BSMCs lack CEBP- $\alpha$. When pretreated with CEBP- $\alpha$ antisense oligonucleotides or with the steroid antagonist RU486, the antiproliferative action of steroids and the downregulation of IL-6 was counterbalanced.

In summary, there is evidence that the lack of the antiproliferative action of steroids in asthmatic BSMCs is based on a lack of the transcription factor CEBP- $\alpha$; this lack can be bypassed by $\beta_{2}$-agonists. The antiproliferative and antiinflammatory signalling pathway of both drug types involves the GR, but splits up subsequently.

M. Roth*, P.R.A. Johnson*, P. Borger*, G. G. King ${ }^{\#}$, Q. Ge ${ }^{\#}$, J. Burgess ${ }^{\#}$, J. Black ${ }^{\#}$, M. Tamm*

*Pulmonary Cell Research University Hospital Basel, Switzerland. " Dept of Pharmacology and Woolcock Institute, University of Sydney, Australia.

\section{Involvement of IKK signalsome complex in $\beta$-catenin signalling pathway regulation in human bronchial epithelial cells}

In asthma, the epithelium is frequently damaged. $\beta$-catenin $(\beta$-cat) is an intracellular protein essential for E-cadherinmediated cell adhesion, but can also act as a transcription factor. The authors have shown that dexamethasone (Dex) induces the formation of $\beta$-cat/Tcf- 4 complex and its translocation in the nucleus where it can activate target gene transcription. The fate of human bronchial epithelial cells (HBEC) including cohesion and repair may be related to these processes. $\beta$-cat, as a transcription factor, has been shown to induce proliferation and inhibit apoptosis of HBEC. In the present study, the molecular process implicated in the Dex-induced $\beta$-cat signalling pathway in HBEC was investigated.

After Dex stimulation of HBEC the $\beta$-cat/Tcf- 4 complex functionality was investigated by transfection and luciferase assay. The implications of the regulatory molecules GSK-3 $\beta$, E-cadherin, IKK- $\alpha$ and IKK- $\beta$, in the Dex-induced $\beta$-cat signalling pathway, were assessed by immunoprecipitation and immunofluorescence.

Luciferase assay showed that $\beta$-cat/Tcf- 4 complex is functional $(\mathrm{p}<0.05)$. Immunoprecipitation and immunofluorescence analysis showed that the Dex-induced $\beta$-cat transcriptional activity was mediated by the IKK signalsome and tightly regulated by GSK-3 $\beta$ and E-cadherin-mediated intercellular adhesion complex.

To conclude, steroids regulated the $\beta$-cat transcriptional activity outside of the canonical Wnt-regulated pathway, by the IKK signalsome complex. This mechanism may be essential in promoting the injury-repair cycle in damaged epithelium of asthmatics.

N. Carayol*, R. Gagliardo ${ }^{\#}$, I. Vachier*, A. M Vignola ${ }^{\#}$, P. Godard*, J. Bousquet*, P. Chanez* *INSERM U454, CHU Montpellier, France. ${ }^{\#}$ IBIM, CNR Palermo, Italy. 
Role of oxidative stress in the regulation of iNOS and arginase in rat alveolar macrophages

L-Arginine is a substrate of nitric oxide synthase (NOS) and arginase, pathways of particular importance in macrophages. Arginase can limit the L-arginine supply for NOS and may be involved in the development of airway hyperreactivity. A role for oxidative stress, known to be associated with acute inflammatory reactions, in the regulation of arginase and inducible (i)NOS in alveolar macrophages (AM) was studied.

Rat AM were cultured for $1-20 \mathrm{~h}$ in the absence or presence of $1 \mu \mathrm{g} \cdot \mathrm{mL}^{-1}$ lipopolysaccharide (LPS) and/or apocynin (NADPH oxidase inhibitor). Nitrite accumulation in culture media and arginase activity at the end of the culture periods were determined or RNA was isolated for use in RT-PCR.

Arginase activity in AM cultured in the absence of LPS was $31 \pm 4 \mathrm{mU} \cdot 10^{6}$ cells $^{-1}$ and presence of LPS caused an increase of $115 \pm 11 \%$. Apocynin $(500 \mu \mathrm{M})$ reduced basal arginase activity by $54 \pm 9 \%$ and largely attenuated the LPS-mediated increase. After 5 and $20 \mathrm{~h}$ of exposure to LPS, arginase I mRNA was clearly increased and apocynin, which slightly reduced basal arginase I mRNA, inhibited the LPS-induced increase. Apocynin also attenuated the LPS-induced increase of iNOS mRNA, but had no clear effect on the expression of arginase II mRNA. Exposure to hydrogen peroxide $\left(\mathrm{H}_{2} \mathrm{O}_{2}\right)$ caused an increase in arginase I mRNA. This effect, started after $1 \mathrm{~h}$, was maximal after $2 \mathrm{~h}$, and was lost after $5 \mathrm{~h}$ of exposure to $\mathrm{H}_{2} \mathrm{O}_{2}$. With a similar time course, exposure to $\mathrm{H}_{2} \mathrm{O}_{2}$ also caused a transient increase in iNOS mRNA (all $\mathrm{n} \geqslant 4$ ).

To conclude, in rat $\mathrm{AM}$ the expression of arginase I mRNA, like that of iNOS mRNA, is highly sensitive to oxidative stress. The inhibitory effect of apocynin on LPSinduced increase in arginase I and iNOS expression suggests that oxygen radicals may play a role as intracellular signals.

\section{K. Racké, D. Lindemann, F. Wenzel}

Institute of Pharmacology and Toxicology, University of Bonn, Bonn, Germany.

\section{Novel roles for elafin in modulating LPS-mediated inflammation}

Elafin is an elastase inhibitor that plays a role in the lung's defence against tissue damage mediated by human neutrophil elastase. The authors have recently demonstrated that, in addition, elafin may contribute to host defence mechanisms both as a "defensin-like" antimicrobial peptide and as a neutrophil chemoattractant. Here, the lipopolysaccharide (LPS)-binding properties of elafin and the effects of this interaction on the inflammatory response of host cells to LPS are described.

Direct binding of elafin to both smooth-form and roughform LPS serotypes was demonstrated using native acidic ( $\mathrm{pH}$ 4.5) polyacrylamide gel electrophoresis techniques. Further, an ELISA assay was used to demonstrate that elafin in the concentration range 10-160 $\mathrm{nM}$ can inhibit the interaction of LPS with the acute-phase serum component LPS-binding protein, an important step in the LPS-mediated activation of macrophages; maximal inhibition observed was $42 \%$ at $160 \mathrm{nM}$ elafin.

To determine the effects of elafin's LPS-binding properties on cellular responses to LPS, the murine macrophage cell line RAW 264.7 was used. Cells were stimulated with $50 \mathrm{ng} \cdot \mathrm{mL}^{-1}$
LPS of Escherichia coli serotype O55:B5 for $4 \mathrm{~h}$ in the presence or absence of $0-100 \mathrm{nM}$ elafin, and secretion of tumour necrosis factor (TNF)- $\alpha$ was measured by ELISA. Cell stimulations were carried out in culture medium either containing or lacking in serum. In medium containing $0.2 \%$ serum, elafin was shown to inhibit LPS-mediated TNF- $\alpha$ release by $35-40 \%$ at $10-100 \mathrm{nM}$. However, in serum-free conditions, elafin increased LPS-induced TNF- $\alpha$ release six-fold at these concentrations indicating an enhancement of activation of cells by LPS.

These findings suggest that the effects of elafin may be dependent upon the site of LPS stimulation in vivo; for example elafin may act to downregulate LPS activity in systemic serum-containing milieu, but may enhance the inflammatory response to LPS in sites where serum is absent, such as the airways. This may have physiological relevance in the control of local lung inflammation while dampening potentially deleterious systemic responses.

\section{J.W. McMichael, J-M. Sallenave}

Rayne Laboratory, Centre for Inflammation Research, University of Edinburgh, UK.

\section{Pulmonary inflammation and promotion of peripheral vascular thrombosis by particulate pollutants}

Pollution by particulates has been associated with cardiopulmonary morbidity and mortality, but biological plausibility for this association is lacking. Ultrafine particles $(<100 \mathrm{~nm})$ are believed to play an important role. Their role was studied in an in vivo hamster model of peripheral vascular thrombosis induced by free radical-mediated endothelial injury, using intravenous Rose Bengal and local illumination. Pulmonary inflammation was assessed by bronchoalveolar lavage (BAL).

First, the acute $(1 \mathrm{~h})$ effects of intratracheally instilled polystyrene particles with differing surface charges was studied. Unmodified $(60 \mathrm{~nm})$ and negatively charged $(60 \mathrm{~nm})$ particles did not affect venous thrombosis or BAL indices. Positively charged $(60 \mathrm{~nm})$ particles increased thrombosis at 500 and $50 \mu \mathrm{g} \cdot$ animal $^{-1}$, but not at $5 \mu \mathrm{g} \cdot$ animal $^{-1}$. Neutrophils, lactate dehydrogenase and histamine were increased in BAL at all these doses. Positive $400 \mathrm{~nm}$ particles $\left(500 \mu \mathrm{g} \cdot \mathrm{animal}^{-1}\right)$ did not affect thrombosis, although they led to an increase in neutrophils, proteins and histamine in BAL.

Using the platelet function analyser, the platelets of hamsters were shown to be activated by the in vitro addition of positive $60 \mathrm{~nm}$ and $400 \mathrm{~nm}$ particles to blood. Subsequent experiments using intratracheally instilled diesel exhaust particles also showed a dose-dependent $\left(5,50,500 \mu \mathrm{g} \cdot \mathrm{animal}^{-1}\right)$ enhancement of venous thrombosis, with evidence of platelet activation and pulmonary inflammation, $1 \mathrm{~h}$ after instillation. The prothrombotic effect was also observed for arterial thrombosis. These effects persisted at 6 and $24 \mathrm{~h}$ after instillation $\left(50 \mu \mathrm{g} \cdot \mathrm{animal}^{-1}\right)$. Preliminary data indicate that these effects can be mitigated by pretreatment with an H1histamine-receptor antagonist (diphenhydramine).

These results provide plausible mechanistic explanations for the epidemiologically established link between air pollution and acute cardiopulmonary effects.

\section{A. Nemmar*, M.F. Hoylaerts ${ }^{\#}$, P.H.M. Hoet*,} B. Nemery*

*Laboratory of Pneumology, Unit of Lung Toxicology, and ${ }^{\#}$ Centre for Molecular and Vascular Biology, K.U. Leuven, Belgium. 
Cigarette smoke and oxidative stress alter histone acetylation and deacetylation in alveolar epithelial cells: potential mechanism in inflammatory gene transcription

Cigarette smoke contains $>10^{15}$ free radicals per puff and many of these are relatively long-lived such as tar-semiquinone, which can generate hydrogen peroxide $\left(\mathrm{H}_{2} \mathrm{O}_{2}\right)$. Cigarette smoke induces an abnormal inflammatory response by upregulation of proinflammatory genes in the lungs of susceptible smokers. Chromatin remodelling by histone acetylation:deacetylation regulates gene transcription by modulating transcription factor accessibility to promoters on genes.

In this study, the effects of cigarette smoke condensate (CSC) and $\mathrm{H}_{2} \mathrm{O}_{2}$ on histone acetylation (histone 4):deacetylation (HDAC 2), nuclear factor (NF)- $\kappa \mathrm{B}$ transactivation and the expression of interleukin (IL)-8 in alveolar epithelial cells (A549) were determined.

Treatment with CSC $(1,5,10 \%)$ and $\mathrm{H}_{2} \mathrm{O}_{2}(100 \mu \mathrm{M})$ significantly increased acetylation of $\mathrm{H} 4$ (210, 385, 590 and $410 \%$, respectively; $\mathrm{p}<0.001)$, compared with control values $(100 \%)$ at $1 \mathrm{~h}$ as detected by immunocytochemistry. CSC $(1,5,10 \%)$ and $\mathrm{H}_{2} \mathrm{O}_{2}(100 \mu \mathrm{M})$ also significantly increased histone acetyltransferase activity (HAT) and protein levels assessed by $\left[{ }^{3} \mathrm{H}\right]$ acetate incorporation assay and Western blotting respectively, compared with the controls. $\mathrm{H}_{2} \mathrm{O}_{2}$ and the HDAC inhibitor, trichostatin A (100 ng. $\left.\mathrm{mL}^{-1}\right)$ increased NF$\kappa \mathrm{B}$ activity (210 and $190 \%$, respectively, versus control $100 \%$ ) as measured by luciferase reporter assay. This was associated with increased coactivator CBP binding with $\mathrm{NF}-\kappa \mathrm{B}$. CSC and $\mathrm{H}_{2} \mathrm{O}_{2}$ treatment also resulted in a decrease in HDAC 2 levels (CSC 60\%, $\mathrm{H}_{2} \mathrm{O}_{2} 52 \%$ versus control $100 \%$; $<<0.01$ ) in A549 cells. $\mathrm{H}_{2} \mathrm{O}_{2}$ exposure also significantly increased IL-8 release $\left(\mathrm{H}_{2} \mathrm{O}_{2} 1.7 \pm 0.29\right.$ versus controls $0.44 \pm 0.11 \mathrm{ng} \cdot \mathrm{mL}^{-1}$, $\mathrm{n}=4 ; \mathrm{p}<0.001)$, and IL-8 gene expression in A549 cells.

Thus, cigarette smoke-derived oxidants modulate intrinsic HAT activity, activate NF- $\mathrm{BB}$ and inhibit HDAC 2 levels leading to increased histone acetylation. This suggests that cigarette smoke induces proinflammatory effects via histone acetylation:deacetylation in epithelial cells.

I. Rahman, F.M. Moodie, J.A. Wickenden, J.A. Marwick, L.A. Jimenez, W. MacNee

ELEGI/Colt Laboratory, University of Edinburgh Medical School, UK.

\section{IL-6 in exhaled breath condensate as an inflammatory marker in pulmonary diseases}

Airway inflammation plays a key role in the pathogenesis of several respiratory diseases. The discovery of noninvasive inflammatory markers may therefore be useful in the diagnosis and in monitoring of these diseases. Interleukin (IL)-6 is a proinflammatory cytokine involved in the resolution of acute and chronic inflammation. The aim of this study was to investigate the presence of the IL-6 in exhaled breath condensate of patients with cystic fibrosis (CF), chronic obstructive pulmonary disease (COPD), bronchiectasis and asthma and to assess its usefulness as an inflammatory marker.

Twenty patients with CF (13 males, 28 \pm 9 yrs), 20 with COPD (17 males, $56 \pm 8$ yrs), 15 with mild asthma (seven males, $30 \pm 4 \mathrm{yrs}$ ), 15 with bronchiectasis (eight males, $43 \pm 6$ yrs) and 15 healthy controls (seven males, $33 \pm 4$ yrs) were recruited. IL- 6 concentrations were measured in their breath condensate by a specific enzyme immunoassay kit.

Higher exhaled IL-6 concentrations were found in patients with $\mathrm{CF}\left(6.4 \pm 0.1 \mathrm{pg} \cdot \mathrm{mL}^{-1}\right), \mathrm{COPD}\left(6.2 \pm 0.1 \mathrm{pg} \cdot \mathrm{mL}^{-1}\right)$, asthma $\left(8.0 \pm 0.1 \mathrm{pg} \cdot \mathrm{mL}^{-1}\right)$, bronchiectasis $\left(7.9 \pm 0.2 \mathrm{pg} \cdot \mathrm{mL}^{-1}\right)$ compared with control subjects $\left(2.6 \pm 0.1 \mathrm{pg} \cdot \mathrm{mL}^{-1}\right)$. A further increase in IL-6 levels during exacerbations of these diseases was also observed.

These results suggest that the measurement of exhaled IL-6 may therefore be of clinical value in diagnosis and monitoring of airway inflammation in these diseases.

\section{G.E. Carpagnano*, E. Bucchioni" ${ }^{\#}$ S.A. Kharitonov", P.J. Barnes \\ *Institute of Respiratory Diseases, University of Bari, Italy.

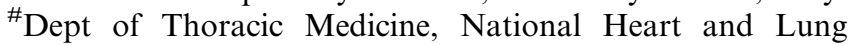 Institute, Imperial College, London, UK.}

STAT4 overexpression in bronchial biopsies from smokers with COPD

The expression of the transcription factor signal transducer and activators of transcription (STAT) 4 is critical for the differentiation of Th1/Tc1 cells and the production of interferon (IFN)- $\gamma$. Phosphorylation of STAT4 on both tyrosine and serine residues is important in promoting STAT4 activation.

The expression and localisation of STAT4, phospho(Y693)STAT4 and IFN- $\gamma$ were investigated in the bronchial mucosa of patients with chronic obstructive pulmonay disease (COPD), and the relationship between their expression and disease status was examined. Bronchial biopsies were obtained from 12 smokers with COPD (59 \pm 16 FEV1 \% predicted), 14 smokers with normal lung function (106 \pm 12 FEV1 $\%$ pred) and 12 nonsmokers with normal lung function $(111 \pm 14$ FEV1 \% pred).

The number of STAT4, phospho(Y693)-STAT4 and IFN- $\gamma$ $(+)$ cells were quantified by immunohistochemistry in bronchial biopsies from the three groups. Results are expressed as median (range). COPD patients had increased numbers of phospho(Y693)-STAT4+ cells in the submucosa (240 (22-406) versus $125(0-492)$ versus $29(0-511)$ cells $\cdot \mathrm{mm}^{-2}$, respectively; $p<0.05)$ in comparison with both control groups. In all smokers the number of submucosal phospho(Y693)STAT4+ cells correlated with the degree of airflow limitation ( $\mathrm{r}=-0.46, \mathrm{p}=0.022$ ) and with the number of submucosal IFN$\gamma+$ cells $(\mathrm{R}=0.45, \mathrm{p}=0.041)$.

To conclude, bronchial biopsies in smokers with mild/moderate COPD show increased activation of STAT4 protein in the submucosa suggesting an increased presence of Th1/Tc1 cells.

S.E. D'Anna*, A. Capelli*, M. Lusuardi*, B. Balbi ${ }^{*}$, P. Balbo ${ }^{\#}$, C. F. Donner*, A. Di Stefano*

${ }^{*}$ S. Maugeri Foundation, IRCCS, Division of Pulmonary Disease, Verona and ${ }^{\#}$ Pavia, Pneumology Unit, Novara, Italy.

\section{Terbutaline improves ischaemialreperfusion injury after left-sided orthotopic rat lung transplantation}

$\beta_{2}$-Agonists have been shown to increase alveolar fluid resorption, and at least part of their effect depends on active sodium transport from the alveolus into the epithelial cell by the amiloride-sensitive epithelial sodium channel. Few data exist on their effect in the inflamed lung. Therefore the effect of intrabronchially administered terbutaline was investigated one day after experimental transplantation of donor lungs with very severe injury due to prolonged ischaemia.

Orthotopic single left-sided lung isotransplantation was 
performed in female rats (Wistar to Wistar, $234 \pm 13 \mathrm{~g}$ $($ mean $\pm \mathrm{SD}))$ after a total ischaemic time of $20 \mathrm{~h}$.

Graft arterial oxygen tension $\left(\mathrm{Pa}, \mathrm{O}_{2}\right)$ /inspiratory oxygen fraction $\left(F \mathrm{I}, \mathrm{O}_{2}\right)$ in six recipients treated with $100 \mu \mathrm{M}$ terbutaline in $500 \mu \mathrm{L} \mathrm{NaCl} 0.9 \%$, instilled into the left lung immediately before reimplantation, was superior $24 \mathrm{~h}$ after transplantation with a $P \mathrm{a}, \mathrm{O}_{2}$ of $329 \pm 111 \mathrm{mmHg}$ versus five controls with $44 \pm 15 \mathrm{mmHg}(\mathrm{p}=0.004)$. The coadministration of terbutaline and $10^{-4} \mathrm{M}$ of the sodium channel blocker amiloride in three recipients abrogated graft $\mathrm{Pa}, \mathrm{O}_{2} / F \mathrm{I}, \mathrm{O}_{2}$ of control level with $71 \pm 34 \mathrm{mmHg}$.

Terbutaline at a high dose significantly improved the transplanted rat lung function at $24 \mathrm{~h}$ after transplantation. As the effect could be blocked by amiloride, part of the mode of action may be due to increased epithelial sodium transport, thus an effect of oedema resorption was shown in this acute lung injury model.

\section{J. Hamacher, R. Lucas, A. Wendel}

Biochemical Pharmacology, University of Konstanz, Konstanz, Germany.

\section{The role of GM-CSF for the development of pulmonary emphysema in SP-D-deficient mice}

Surfactant protein (SP)-D has important functions in the modulation of the inflammatory response. At least some of the changes in SP-D-knockout mice may therefore be due to an uninhibited inflammatory process. In addition to an increased production of matrix metalloproteinases and granulocyte/macrophage colony-stimulating factor (GM-CSF), these lungs are characterised by an enhanced number of enlarged macrophages and pulmonary emphysema. This raises the question of whether the changes in lung morphology are due to a secondary upregulation of GM-CSF.

The aim of this study was to quantify the pulmonary emphysema in SP-D and GM-CSF single-knockout mice compared with SP-D/GM-CSF double-knockout mice by means of unbiased stereological methods. Besides classical estimators a new method was applied, based on the so-called Euler number estimation to determine the number of alveoli and to calculate alveolar size. The authors were also interested in how the number and size of alveolar macrophages and type-II pneumocytes coincided with the degree of pulmonary emphysema. Therefore, they made use of the physical disector and rotator method.

Both the GM-CSF- and the SP-D-knockout mice were afflicted with an emphysema of a similar degree. Whereas the number of alveolar macrophages in GM-CSF-knockout mice seemed to be normal, the SP-D-knockout mice showed an increased number and size. Regarding the double-knockout mice, a significantly higher degree of pulmonary emphysema was found although the number of alveolar macrophages was, as opposed to the size, not increased.

To conclude, these data suggest that SP-D deficiency does not lead to pulmonary emphysema via an upregulation of GM-CSF. Instead GM-CSF seems to be necessary for proliferation and hypertrophy of both alveolar macrophages and type-II pneumocytes in SP-D-knockout mice. Moreover, SP-D deficiency and GM-CSF deficiency seem to have additive effects on emphysema development.

\section{Knudsen*, M. Ochs*, S. Hawgood ${ }^{\#}$}

*Dept of Anatomy, University of Goettingen, Germany. ${ }^{\#}$ Cardiovascular Research Institute, University of California, San Francisco, CA, USA.
Resolution of airway eosinophilic inflammation in vivo involves egression of granulocytes into the airway lumen rather than apoptosis of airway tissue eosinophils

Based on in vitro data it is believed that apoptosis of granulocytes, especially steroid-induced eosinophil apoptosis, followed by ingestion by macrophages may resolve airway inflammation. This hypothesis was previously tested by examination of thousands of individual eosinophils in tissue specimens obtained from patients with asthma and rhinitis without detecting any apoptotic eosinophil, inside or outside macrophages. The present study examined the effects on resolution of established eosinophilic inflammation in mouse lungs by local treatment with either anti-Fas monoclonal antibody $(\mathrm{mAb})$ or airway steroids.

Immunised and ovalbumin-challenged mice with an established eosinophilia were treated with either anti-Fas $\mathrm{mAb}$ (30 $\mu \mathrm{g}$ intranasally, once) or budesonide $\left(1 \mathrm{mg} \cdot \mathrm{kg}^{-1}\right.$ intraperitoneally for 4 days). Bronchoalveolar lavage fluid (BALF) and lung tissues were obtained 8,24 and $96 \mathrm{~h}$ after the treatments. Luminal entry was determined as BALF eosinophils. Apoptosis in the airway lumen was analysed morphologically on cytospin slides and apoptosis in the tissue was assessed by transmission electron microscopy (TEM) and TUNEL-staining.

Prolonged steroid treatment $(96 \mathrm{~h})$ permitted luminal entry of eosinophils (BALF eosinophilia was not reduced) and reduced the tissue eosinophilia without any signs of apoptosis. Anti-Fas treatment induced apoptosis of lung tissue eosinophils ( $5 \%$ after $24 \mathrm{~h}$ ) as confirmed by TEM but the eosinophilia remained. Neighbouring macrophages left the apoptotic eosinophils unengulfed leading to secondary necrosis of these cells and a general aggravation of lung inflammation with upregulation of CC-chemokines, increased mucus-exudate plugs, eosinophil cytolysis and cell debris $(\mathrm{p}<0.05)$

To conclude, eosinophil apoptosis is a rare event in vivo in airway tissues even at steroid-mediated resolution. With enforced eosinophil apoptosis, secondary necrosis and aggravated inflammation resulted rather than efficient engulfment of the apoptotic cells. Noninjurious elimination of airway tissue eosinophils occurs through egression into the airway lumen rather than through apoptosis.

\section{Uller*, C.G.A. Persson ${ }^{\#}$, J.S. Erjefält*}

*Dept of Physiological Sciences and ${ }^{\#}$ Dept of Clinical Pharmacology, Lund University, Lund, Sweden.

\section{IL-4 enhances wound rate closure in lung epithelial cells that is EGFR-dependent and induces activation of $E R K 1 / 2$}

Goblet cell hyperplasia and mucus hypersecretion are important features in the pathogenesis of asthma. Studies using cultured airway epithelial cells as well as animal studies have indicated that epithelial mucin production is, at least in part, regulated by the epidermal growth factor receptor (EGFR). The EGFR is also a crucial mediator in epithelial remodelling and repair processes. Increasing evidence obtained from in vivo and cell culture studies points to a role of the T-helper cell (Th) type-2 cytokines interleukin (IL)-4, IL-9 and IL-13 in goblet cell hyperplasia and mucus hypersecretion. However, the effect of Th2 cytokines on epithelial repair is unclear. Therefore, the aim of this study was to examine the effect of IL-4 on airway epithelial wound closure and the involvement of the EGFR. 
Using H292 and 16HBE bronchial epithelial cells it was observed that IL-4 induced a time- and dose-dependent enhancement of the wound closure. The stimulatory effects of IL-4 were observed at concentrations of $10 \mathrm{ng} \cdot \mathrm{mL}^{-1}$ and higher. A significant difference in wound closure was already observed after $24 \mathrm{~h}$, but was most prominent between 48-72 $\mathrm{h}$ where the closure rate in the presence of IL-4 was 1.5-2-fold higher compared with control-treated cells. In the presence of an antibody against the EGFR these effects were completely abolished. Following activation of the EGFR, stimulation of various signalling pathways occurs, including activation of extracellular signal-related kinase (ERK)1/2. Therefore, the effect of IL-4 on ERK1/2 activation was also studied. IL-4 induced ERK1/2 activation within $5 \mathrm{~min}$ that persisted up to $20 \mathrm{~min}$ and was prevented by the EGFR inhibitor AG1478 and the mitogen-activated protein kinase kinase (MEK) inhibitor U0126, which prevent activation of the MEK pathway. These results indicate that the Th2 cytokine IL-4 promotes epithelial restitution that involves activation of the EGFR and downstream signalling pathways.

\section{S. van Wetering, K.F. Rabe, P.S. Hiemstra}

Dept of Pulmonology, LUMC, Leiden, The Netherlands.

\section{Cellular infiltrates and injury evaluation in a rat model} of warm ischaemialreperfusion in lung tissue

Besides lung transplantation, thoracic surgery and pulmonary embolism result in serious pulmonary ischaemia/ reperfusion injury. Therefore, a model of warm ischaemia/ reperfusion injury was developed to differentiate cellular infiltrates and to quantify tissue damage.

Fifty rats were randomised into eight groups. Five groups underwent warm ischaemia during $60 \mathrm{~min}$ followed by $30 \mathrm{~min}, 1,2,3$ and $4 \mathrm{~h}$ of warm reperfusion, respectively ( $n=7$ each). An additional group was flushed with buffered starch during $4 \mathrm{~min}$ by using isolated lung perfusion (ILuP) after $4 \mathrm{~h}$ of reperfusion $(\mathrm{n}=7)$. One of two sham groups was also flushed with buffered starch using ILuP ( $n=4$ each). Samples processed with haematoxylin and eosin were used in order to visualise neutrophils and oedema. Immunohistochemistry with ED-1 and 1F4 was applied to visualise macrophages and T-cells, respectively. Apoptotic cells and bodies were stained by the TUNEL method. Statistical significance was accepted at $\mathrm{p}<0.05$.

Neutrophils were increased after $30 \mathrm{~min}$ until $4 \mathrm{~h}$ of reperfusion, as well as after flushing. Doubling of macrophages and a four-fold increase of T-cells were observed after 30 min until 1 and $2 \mathrm{~h}$ of reperfusion, respectively. Apoptosis with important oedema in the absence of necrosis was seen during the whole study period.

After warm ischaemia/reperfusion, an important increase in infiltration of neutrophils, a four-fold increase of T-cells and doubling of macrophages were observed in this study. Warm ischaemia/reperfusion followed by flushing also resulted in a significant increase in infiltration of neutrophils. Finally, this study showed apoptosis with serious oedema in the absence of necrosis after all periods of reperfusion.

B.P. van Putte, V.P. Persy, J.M.H. Hendriks, V. van der Meiren, M.E. De Broe, P.E.Y. van Schil

Depts of Thoracic and Vascular Surgery and Nephrology, University Hospital Antwerp, Edegem, Belgium.
Cytotoxic effects of infection with rhinovirus on asthmatic primary bronchial epithelial cells

Rhinovirus (RV) is an important trigger of acute asthma and in vitro studies have shown that infection of epithelial cells leads to the release of proinflammatory mediators. Although cytopathic effects of RV have been reported, the underlying mechanisms of cell death have not been elucidated. The aim of this study was to analyse cell death following infection and to relate this to virus production and the inflammatory response of the epithelial cells.

Primary bronchial epithelial cells (PBEC) were obtained by bronchial brushings and grown to confluence, then serum starved for $12 \mathrm{~h}$. Cells were treated with RV-16 and measurements taken between $8-48 \mathrm{~h}$. Cells were photographed under time-lapse phase contrast microscopy; they were then analysed by flow cytometry using Annexin-V and 7AAD to detect apoptosis or necrosis. Supernatants were removed and assayed for lactate dehydrogenase (LDH) activity or ELISAs performed for measurement of interleukin (IL)-8 and tumour necrosis factor- $\alpha$.

As previously reported, RV-infected cells demonstrated a significant increase in IL-8 release that was evident at $24 \mathrm{~h}$ and maximal by $48 \mathrm{~h}$. However, in these cultures, the cytopathic effect of RV was evident $2 \mathrm{~h}$ after infection, with cells increasing in size and detaching. By $8 \mathrm{~h}$, there was a higher proportion of necrotic cells $(41 \%)$ compared with controls $(14 \%, \mathrm{p}<0.001)$, but no significant difference in apoptotic cells. A significant rise in LDH activity was not seen at $8 \mathrm{~h}$ but was evident $48 \mathrm{~h}$ postinfection $(83 \%$ of total cellular LDH released, $\mathrm{p}<0.001$ )

Infection of PBEC with RV leads to significant cell necrosis evident by $8 \mathrm{~h}$ that precedes the release of IL- 8 from cells. The extent of cell death appears to be in excess of that which could be accounted for by the initial RV infection, and may result from secondary release of virions or cytotoxic factors from affected cells.

P.A.B. Wark*, F. Bucchieri*, S.M. Puddicombe*, A.L. Andrews*, S.L. Johnston ${ }^{\#}$, D.E. Davies*, S.T. Holgate*

*Brooke Laboratories, Southampton General Hospital, Southampton, and ${ }^{\#}$ Dept of Respiratory Medicine, National Heart and Lung Institute at St Mary's Imperial College, School of Medicine, London, UK.

Specific modulation of CaM activity induces a dramatic production of superoxide by alveolar macrophages

Airway inflammation is a characteristic feature in airway diseases such as asthma and chronic obstructive pulmonary disease. Oxidative stress, caused by the excessive production of reactive oxygen species (ROS) by inflammatory cells like macrophages, eosinophils and neutrophils, is thought to be important in the complex pathogenesis of such airway diseases. The calcium-sensing regulatory protein calmodulin $(\mathrm{CaM})$ binds and regulates different target enzymes and proteins, including calcium channels. In the present study, it was investigated whether CaM, via the modulation of calcium channel function, influences intracellular calcium concentration in pulmonary inflammatory cells, and consequently, modulates the production of ROS by these cells. This was tested with a peptide termed calcium-like peptide 2 (CALP2), which was previously shown to regulate such channels. Specifically, radical production by purified bronchoalveolar lavage cells from guinea-pigs in response to CALP2 was 
measured. CALP2 was a strong activator of alveolar macrophages. In contrast, CALP2 was only a mild activator of neutrophils and did not induce radical production by eosinophils. The CALP2-induced radical production was mainly intracellular, and was completely blocked by the reduced nicotinamide adenine dinucleotide phosphate-oxidase inhibitor DPI, the superoxide inhibitor superoxide dismutase, and by the CaM antagonist W7. Furthermore, the calcium channel blocker lanthanum partly inhibited the cellular activation by CALP2. It was concluded that alveolar macrophages, but not neutrophils or eosinophils, can produce extremely high amounts of ROS when stimulated via the calcium/CaM pathway. These results may contribute to new therapeutic strategies against oxidative stress in airway diseases.

R. Ten Broeke, A. Leusink-Muis, R. Hilberdink, I. van Ark, M. Villain, F. De Clerck, J.E. Blalock, F.P. Nijkamp, G. Folkerts

Dept of Pharmacology and Pathophysiology, Utrecht Institute for Pharmaceutical Sciences, Utrecht University, The Netherlands.

\section{The myeloid-related protein-8/14 heterodimer is the predominant stimulator of epithelial IL-8 in airway secretions}

The myeloid-related protein (MRP)-8/14 heterodimer (S100A8/A9; calprotectin) constitutes $60 \%$ of neutrophilic cytoplasmic protein and is a member of the S100 family of calcium-binding proteins. It is elevated in a number of inflammatory disorders such as inflammatory bowel disease, rheumatoid arthritis and cystic fibrosis. Although it has been shown to exhibit antimicrobial properties and may inhibit tumour invasiveness, the functions of MRP-8/14 remain largely unexplored and unlike its contemporary S100 molecules, it is not directly chemotactic.

It was found that MRP-8/14 is present in sputum sol phase from patients with chronic obstructive pulmonary disease and its concentration is associated (Spearman's rank correlations) with sputum concentrations of myeloperoxidase $(\mathrm{r}=0.811, \mathrm{p}<0.01 ; \mathrm{n}=28)$, neutrophil elastase $(\mathrm{r}=0.894$, $\mathrm{p}<0.01 ; \mathrm{n}=16)$, interleukin (IL) $-8 \quad(\mathrm{r}=0.585, \mathrm{p}=0.01 ; \mathrm{n}=28)$ and sputum colour number $(\mathrm{r}=0.87, \mathrm{p}<0.001 ; \mathrm{n}=28)$. Furthermore, size exclusion chromatography of sputum sol phase suggests that MRP-8/14 is a key stimulator of IL-8 secretion from airway epithelial cells in vitro $\left(898 \pm 16 \mathrm{pg}\right.$ IL- $8 \times 10^{6}$ stimulated cells versus $374 \pm 19$ pg IL- $8 \times 10^{6}$ control cells, $\mathrm{p}<0.001)$.

Since IL-8 is a major neutrophil chemoattractant, this alludes to a potentially pivotal role of MRP-8/14 in the propagation of neutrophil-mediated inflammation in bronchial disease.

A. Ahmad, D. Bayley, N. Carrabino, R. Stockley

University of Birmingham, Birmingham, UK.

\section{Inflammatory cells within the airway smooth muscle in COPD}

A mast cell infiltration of airway smooth muscle has been reported in patients with asthma. To determine if this infiltration is a specific feature of asthma or a general characteristic of obstructive airway diseases, the localisation of inflammatory cells within the airway smooth muscle of smokers with chronic ostructive pulmonary disease (COPD) was investigated.

Using immunohistochemical methods, the number of mast cells, neutrophils and macrophages infiltrating the smooth muscle of peripheral airways were quantified. Surgical specimens were obtained from three groups of subjects undergoing thoracotomy for localised pulmonary lesions: 10 smokers with symptoms of chronic bronchitis and fixed airflow limitation (FEV1 $66 \pm 3 \%$ predicted), six asymptomatic smokers with normal lung function (FEV1 $102 \pm 4 \%$ pred) and nine asymptomatic nonsmoking controls with normal lung function (FEV1 106 $\pm 6 \%$ pred).

The number of neutrophils was significantly increased in both smokers with COPD (54 (9-93) cells $\cdot \mathrm{mm}^{-2}$ ) and smokers with normal lung function $\left(33(11-77)\right.$ cells $\left.\cdot \mathrm{mm}^{-2}\right)$ compared with nonsmokers $\left(6(0-38)\right.$ cells $\left.\cdot \mathrm{mm}^{-2}\right), \mathrm{p}=0.0014$ and $\mathrm{p}=0.017$, respectively. The number of mast cells and macrophages was not different in the three groups examined. When all subjects were considered together, the number of neutrophils within airway smooth muscle showed a negative correlation with both the values of FEV1 \% pred $(\mathrm{r}=-0.53$, $\mathrm{p}=0.009)$ and FEV1/ FVC \% ( $\mathrm{r}=-0.47, \mathrm{p}=0.022)$.

To conclude, at variance with asthma, mast cell infiltration of airway smooth muscle is not a feature characteristic of COPD. By contrast, in this disease the neutrophil appears to be the predominant cell infiltrating the airway smooth muscle. The correlation observed between the neutrophil number and the degree of airway obstruction suggests a possible role for these cells in the remodelling of peripheral airways that characterises COPD.

S. Baraldo*, G. Turato*, C. Badin*, A. Papi ${ }^{\#}$, GL. Casoni ${ }^{\#}$, B. Beghè*, R. Zuin*, P. Maestrelli*, L.M. Fabbri ${ }^{\oplus}$, M. Saetta*

*Universities of Padova, ${ }^{\#}$ Ferrara and ${ }^{\top}$ Modena and Reggio Emilia, Italy.

\section{Decreased TIMP-1 and TGF- $\beta$ in cultured alveolar macrophages from patients with $C O P D$}

Alveolar macrophages (AM) are key cells in the development of the inflammatory process. There is increasing evidence that AM play a role in the pathogenesis of chronic obstructive pulmonary disease (COPD). In this study, the concentration of several inflammatory mediators (tissue inhibitor of metalloproteinase (TIMP)-1, matrix metalloproteinase (MMP)-9,

Table 1.-Tissue inhibitor of metalloproteinase (TIMP)-1 and transforming growth factor (TGF)- $\beta$ levels in chronic obstructive pulmonary disease (COPD)

\begin{tabular}{|c|c|c|c|c|}
\hline & \multicolumn{2}{|c|}{ TIMP-1 ng $\cdot \mathrm{mL}^{-1}$} & \multicolumn{2}{|c|}{ TGF $-\beta \mathrm{pg} \cdot \mathrm{mL}^{-1}$} \\
\hline & Baseline & LPS & Baseline & LPS \\
\hline \multicolumn{5}{|l|}{ COPD } \\
\hline $4 \mathrm{~h}$ & $1.7 \pm 0.4$ & $2.4 \pm 0.8$ & ND & ND \\
\hline $24 \mathrm{~h}$ & $4.2 \pm 2.1$ & $6.9 \pm 4.9$ & $17 \pm 5$ & $67 \pm 13$ \\
\hline \multicolumn{5}{|c|}{ Smokers } \\
\hline $4 \mathrm{~h}$ & $5.7 \pm 2$ & $7.4 \pm 2.6$ & ND & ND \\
\hline $24 \mathrm{~h}$ & $28.3 \pm 10.9$ & $33.5 \pm 12.2$ & $25.9 \pm 6.6$ & $109.6 \pm 10.4$ \\
\hline \multicolumn{5}{|c|}{ Never-smokers } \\
\hline $4 \mathrm{~h}$ & $10 \pm 3$ & $15.2 \pm 4.7$ & ND & ND \\
\hline $24 \mathrm{~h}$ & $69.5 \pm 17.6$ & $73 \pm 24.2$ & $13.9 \pm 5.1$ & $135 \pm 54.5$ \\
\hline
\end{tabular}

Data are presented as mean \pm SEM. LPS: lipopolysaccharide; ND: not detectable. 
transforming growth factor (TGF)- $\beta$ and leukotriene (LT)B $\mathrm{B}_{4}$ ) released by cultured AM (at 4 and $24 \mathrm{~h}$, with and without lipopolysaccharide stimulation) obtained from bronchoalveolar lavage samples in 17 COPD patients $(65 \pm 2$ yrs, $59 \pm 5$ packyrs, FEV1 $56 \pm 4 \%$ (mean \pm SEM) predicted), 17 smokers with normal lung function ( $55 \pm 2$ yrs, $42 \pm 4$ pack-yrs, FEV1 $97 \pm 4 \%$ pred) and seven never-smokers (67 \pm 7 yrs, FEV1 94 $\pm 4 \%$ pred) were determined by ELISA. Results show that: 1) TIMP-1 and TGF- $\beta$ levels were lower in COPD patients $(\mathrm{p}<0.05)$ than in the other two groups (table 1); and 2) MMP-9 and $\mathrm{LTB}_{4}$ levels were similar in all groups (data not shown).

These results show that AM harvested from patients with COPD release low antielastolytic and anti-inflammatory mediators than smokers and never-smokers with normal lung function.

J. Sauleda, A.R. Pons, J. Pons, A. Noguera, B. Barceló, A. Fuster, A.G.N. Agustí

Servei de Pneumologia, Servei d'Anàlisis Clínics and Unitat d́Investigació, Hospital Universitari Son Dureta, Palma de Mallorca, Spain.

\section{The Th1/Th2 paradigm in bronchoalveolar lavage from} children with asthma

There is increasing evidence that T-helper cell (Th) type-2 cytokines play a pivotal role in the pathogenesis of asthma. However, no published studies have investigated the cytokine production at the single cell level in paediatric bronchoalveolar lavage fluid (BALF). The aim of this study was to simultaneously detect surface markers and intracellular production of cytokines in T-cells from the airways of children with and without asthma.

BALF was obtained by a nonbronchoscopic lavage technique immediately prior to elective surgery. A total of 60 subjects were included in this study (39 male, median age 7.79 yrs, range 2.08-13.92), which included 18 atopic asthmatics, 14 nonasthmatic atopic subjects and 29 normal control subjects. Cells were stimulated with phorbol myristate acetate and ionomycin, and intracytoplasmic cytokine retention was achieved using monensin. Cells were stained with the relevant antibodies and analysed flow cytometrically.

Unstimulated cells did not express detectable levels of intracellular cytokines, even in the presence of monensin. No statistical difference was observed in the percentage of CD3+ cells that produced interleukin (IL)-2 or -4 between atopic asthmatics, atopic nonasthmatic subjects and normal controls. However, it was noted that the use of inhaled corticosteroids was associated with a significant reduction in the percentage of IL- $4+/ \mathrm{CD} 3+$ cells $(\mathrm{p}=0.008, \mathrm{n}=5)$. The percentage of interferon (IFN)- $\gamma+\mathrm{T}$-cells was significantly increased in atopic asthmatics (median $71.3 \%$, interquartile range 65.1-82.2, $\mathrm{n}=13$ ) compared with both atopic nonasthmatic subjects $(51.9 \%, 37.2-70.3, \mathrm{n}=12 ; \mathrm{p}<0.05)$ and normal controls $(58.1 \%, 36.1-66.1, \mathrm{n}=23 ; \mathrm{p}<0.01)$.

These findings indicate that IFN- $\gamma$-producing $\mathrm{T}$-cells are more abundant in the airways of children with atopic asthma compared with atopic nonasthmatic subjects and controls. The proinflammatory activities of IFN- $\gamma$ may play an important role in the pathogenesis of childhood asthma and may suggest that asthma is not simply a Th2-driven response.

\footnotetext{
V. Brown, T.J. Warke, M.D. Shields, M. Ennis

Depts of Clinical Biochemistry and Child Health, Queen's University Belfast, Belfast, UK.
}

The effect of mometasone furoate on gene expression in primary human lung fibroblasts

Inhaled steroids are important modifiers of airway inflammation and remodelling. However, the exact mechanisms are still largely unknown. The effect of mometasone furoate (MF), a potent synthetic glucocorticoid, was investigated on gene expression in primary lung fibroblasts.

Purified mRNA from human lung fibroblasts treated with either MF, formoterol or MF/RU486 was reverse-transcribed and hybridised onto oligonucleotide microarrays (HG-U133a; Affymetrix, Santa Clara, CA, USA). Gene expression was measured at seven different time points up to $6 \mathrm{~h}$ after treatment with MF or formoterol. Group differences were assessed after standardisation with the Kruskal-Wallis test. Significantly dysregulated genes were further analysed by cluster analysis.

Of the 44,760 total gene sequences, 9,898 (22.1\%) were expressed. One hundred and five $(1.1 \%)$ genes were significantly dysregulated. Genes significantly transactivated by MF $(\mathrm{n}=53)$ included WNT1-inducible signalling pathway protein 1 and insulin-like growth factor-binding protein 2. Several genes involved in inflammation and remodelling, such as interleukin (IL)-6, IL-8, leukaemia inhibitory factor, matrix metalloproteinase-1, and hyaluronan synthase 2, were transrepressed $>50 \%$ by $\mathrm{MF}(\mathrm{n}=52)$. This effect was completely reversed by simultaneous treatment with the glucocorticoidantagonist RU486. The expression of collagen genes was not influenced by MF.

These data suggest that MF modulates expression of relevant genes involved in airway inflammation. The reduction of hyaluronan synthase transcripts may indicate a regulatory effect in airway remodelling.

\section{Joos, E. Eryüksel, J.J. Rüdiger, M. Hermann, K. Laule-Kilian, A.P. Perruchoud, M. Tamm, M.H. Brutsche}

Pulmonary Cell Research Laboratory, University Hospital Basel, Basel, Switzerland.

\section{The role of toll-like receptors in the regulation of neutrophilic lung inflammation}

Neutrophils express toll-like receptors (TLR)2 and TLR4, and respond to lipopolysaccharide (LPS) with prolongation of lifespan that is in part monocyte-dependent. Commercial LPS can stimulate both TLR2 and TLR4, and there is increasing evidence that these receptors can mediate independent responses.

The proinflammatory responses activated in highly purified neutrophils by selective TLR2 and TLR4 agonists, and the signalling pathways mediating these responses were investigated. Activation of either receptor induced changes in adhesion molecule expression with shedding of L-selectin and upregulation of CD11b expression, cytokine generation with significant upregulation of interleukin-8 protein generation, modulation of chemokine receptor expression with loss of cell surface CXCR2, and respiratory burst.

Prolongation of neutrophil lifespan measured by flow cytometry and cellular morphology was a marked feature of TLR4 stimulation, but was much less evident with a TLR2 ligand. Inhibitors of pathways regulating gene transcription exerted differential effects on TLR4-induced 
cytokine generation versus TLR4-induced neutrophil survival.

\section{Sabroe, L.R. Prince, E.C. Jones, S.K. Dower, M.K.B. Whyte}

Academic Unit of Respiratory Medicine, Section of Functional Genomics, Division of Genomic Medicine, University of Sheffield, Royal Hallamshire Hospital, Sheffield, UK.

The effect of Pseudomonas aeruginosa and pyocyanin on neutrophil apoptosis in vivo

Pseudomonas aeruginosa, a human opportunistic pathogen, colonises the lungs of patients with cystic fibrosis (CF) and is a major cause of $\mathrm{CF}$ pulmonary damage and mortality. Polymorphonuclear neutrophils (PMN), recruited to the lungs by chemotactic signals, cytokines and cell adhesion molecules, function to phagocytose the invading bacteria.

Pyocyanin, a phenazine pigment produced by $P$. aeruginosa, induces apoptosis of peripheral blood PMN. This may favour bacterial evasion of host defences but could also protect the host against tissue damage associated with persistent accumulation of inflammatory cells. The effect of wildtype (PA14) and phenazine-deficient (DeltaphnAB) strains of $P$. aeruginosa upon neutrophil accumulation, apoptosis and bacterial clearance in C57BL/6 mice were therefore compared.

Bacterial colony-forming units (cfu) $\times 10^{7}$ were instilled intratracheally and, at time points up to $72 \mathrm{~h}$, bronchial alveolar lavage (BAL) was performed or whole lungs removed. Total neutrophil numbers in BAL fluid were assessed and apoptotic neutrophils were counted by morphology on Diff-Quick-stained cytospins. Serially dilute homogenised lung tissue was cultured overnight and cfu counted. Total BAL neutrophil numbers in DeltaphnAB-infected mice were significantly higher at $48 \mathrm{~h} \quad\left(6.52 \pm 0.87 \times 10^{6}\right)$ compared with PA14-infected mice $\left(4.26 \pm 1.96 \times 10^{5}\right.$, $\mathrm{p}<0.001)$. Phenazine-producing $P$. aeruginosa strains showed significantly enhanced neutrophil apoptosis $(20 \pm 7 \%)$, at $72 \mathrm{~h}$ compared with phenazine-deficient strains $(7 \pm 2 \%, \mathrm{p}<0.01)$ and significantly reduced bacterial clearance $(4.43 \pm 0.55$ versus $1.18 \pm 0.53 \log _{10} \mathrm{cfu}, \mathrm{p}<0.01$ ) at $48 \mathrm{~h}$.

To conclude, phenazine-producing strains showed enhanced neutrophil apoptosis and reduced bacterial clearance when compared with infection by a nonphenazine-producing strain of $P$. aeruginosa. This provides in vivo evidence that pyocyanin production contributes to $P$. aeruginosa evasion of neutrophil host defences.

\section{Allen, D. Dockrell, P. Hellewell, M. Whyte}

University of Sheffield, Sheffield, UK.

\section{Mutation analysis of the human IL-18 intron-1 promoter in sarcoidosis: a possible role for single nucleotide polymorphisms in expression regulation}

Sarcoidosis is a multisystemic disease of unknown aetiology, characterised by a granulomatous inflammatory process. The primary manifestation of the disorder is an accumulation of mononuclear inflammatory cells, mostly activated CD4+ T-helper cell type-1 T-lymphocytes that produce interleukin (IL)-2. IL-18, a proinflammatory cytokine, is important in the pathogenesis of sarcoidosis, via its activator protein-1 and nuclear factor- $\kappa \mathrm{B}-$ mediated regulation of IL-2 gene transcription and protein production. In two of three sarcoidosis patients, spontaneous remission occurs and the remaining patients develop a chronic/progressive form of the disease. Resolution of sarcoidosis correlates with high levels of IL18 in the lung. This study sought to determine whether mutations in the regulatory regions of the IL-18 gene influence physiological levels of this cytokine and thus contribute to disease phenotype. Mutation detection was performed using single strand conformation polymorphism and restriction fragment length polymorphism analyses and sequencing. Single nucleotide polymorphisms (SNPs) were identified and screened in 80 sarcoid patients and 80 healthy controls. The functional consequences of these mutations were assessed using reporter gene assays. Nine sequence variations were detected in this case-control study. Using the Genomatix Matinspector program, it was found that four SNPs are positioned at important transcription factorbinding sites including sequences specific for the GATAbinding proteins. Results indicated that the most common allele (T1336) in the IL-18 intron-1 promoter region was significantly associated with sarcoidosis. Predominant promoter haplotypes were identified in the Irish population. Functional consequences of these haplotypes on transcriptional control were assessed. All IL-18 promoter haplotypes were found to have promoter activity. Regulation of IL-18 promoter activation was elucidated in vitro by exposing transfected cells to various stimuli. Polymorphisms in the IL-18 intron-1 promoter region may play a role in sarcoidosis by upregulating IL-18 expression. The IL-18 1366T/C promoter polymorphism showed an association with sarcoidosis patients, due primarily to an increased frequency of the T-allele.

D. Kelly, P. Gallagher, C. Greene, C. Taggart, G. Meachery, S. O'Neill, N.G. McElvaney

Dept of Respiratory Research, Royal College of Surgeons ERC, Beaumont Hospital, Dublin, Ireland.

\section{Pulmonary eosinophils and T-lymphocytes possess distinct roles in the extension of bleomycin-induced lung injury and fibrosis}

Pulmonary eosinophil accumulation is a common characteristic of lung injury and fibrosis both in human and in animal models. In this study, the role of eosinophils in the cellular and molecular mechanisms of bleomycin (blm)-induced tissue repair and fibrosis were investigated by studying, in particular, their intimately associated cytokine interleukin (IL)-5.

Overexpression of IL-5 by using transgenic mice (IL-5 ${ }^{\mathrm{TG}}$ ) or adenoviral constructs (adIL-5) was associated with a more marked lung fibrosis as well as a massive eosinophil infiltration in comparison with appropriate controls. Surprisingly, blm-treated IL-5-deficient mice (IL-5-/-) developed a more pronounced pulmonary fibrosis accompanied by a greater infiltration of T-lymphocytes compared with wildtype mice, despite the relative absence of lung eosinophilia. In culture, purified lung eosinophils from blm-treated IL-5 ${ }^{\mathrm{TG}}$ mice directly stimulated $\alpha$-smooth muscle actin ( $\alpha$-SMA) and type-I collagen expression in lung fibroblasts isolated from the wildtype mice, without affecting cellular proliferation rate.

Lung T-lymphocytes purified from blm-treated IL-5-/- mice were able to stimulate fibroblast proliferation, but, in contrast, unable to induce $\alpha$-SMA and type-I collagen expression. Instillation of purified eosinophils into the lungs of naive and blm-treated wildtype mice resulted in a significant increase in lung hydroxylproline content. Administration of anti-CD3 antibodies inhibited lung fibrosis suggesting a role for 
T-lymphocytes. Pulmonary fibrosis in blm-treated IL-5 ${ }^{\text {TG }}$ mice was preferentially associated with production of transforming growth factor (TGF)- $\beta$ as well as type-2 cytokines, such as IL-4 and IL-13, whereas fibrotic lesions in IL-5-/- animals were accompanied preferentially by TGF- $\beta$ and proinflammatory cytokines, such as tumour necrosis factor- $\alpha$, IL- $1 \beta$ and interferon- $\gamma$.

To conclude, eosinophils and T-cells contribute to the development of blm-induced lung fibrosis by directly stimulating specific functions of fibroblasts potentially via the production of different cytokine patterns.

\section{F. Huaux*, T. Liü, B. McGarry ${ }^{\#}$, M. Ullenbruch ${ }^{\#}$, Z. Xing ", S.H. Phan ${ }^{\#}$ \\ *Unit of Industrial Toxicology, Université Catholique de Louvain, Brussels, Belgium. ${ }^{\#}$ Dept of Pathology, University of Michigan, USA. ${ }^{\top}$ McMaster University, Canada.}

\section{sVEGF-R1: does this explain the paradox of low epithelial lining fluid VEGF in ARDS?}

Vascular endothelial growth factor (VEGF) has been reported to be decreased in the epithelial lining fluid (ELF) of patients with acute respiratory distress synbdrome (ARDS). The mechanism of this reduction is unknown, but is not due to differential inflammatory cell production. Recovery from lung injury is associated with an eight-fold increase in ELF VEGF levels, supporting a role in alveolar repair. The aim of this study was to see if a biological inhibitor of VEGF, soluble VEGF-receptor 1 (sVEGF-R1) is present within ARDS lungs and whether this influences VEGF levels.

Bronchoalveolar lavage (BAL) was performed on 36 patients at the onset of ARDS and nine patients at risk of ARDS and 10 normal subjects. sVEGF-R1 and VEGF were measured by ELISA in plasma and BAL fluid. ELF VEGF levels were calculated using urea dilution.

sVEGF-R1 was detectable in the BAL fluid of 10 of 36 ARDS patients while none was detected in at-risk or normal controls $(\mathrm{p}=0.048)$. Median concentration of VEGF (ELF) was lower in patients with detectable sVEGF-R1 $\left(1,033 \mathrm{pg} \cdot \mathrm{mL}^{-1}\right)$ than those without detectable levels $\left(4,929 \mathrm{pg} \cdot \mathrm{mL}^{-1}, \mathrm{p}=0.0031\right)$. Patients without detectable levels had similar levels as at-risk patients $\left(3,744 \mathrm{pg} \cdot \mathrm{mL}^{-1}\right)$ and normals $\left(5,261 \mathrm{pg} \cdot \mathrm{mL}^{-1}, \mathrm{p}=0.35\right)$. sVEGF-R1 was undetectable in normal serum $(n=5)$ and in only two of 16 ARDS patients' serum suggesting its origin may be pulmonary.

This is the first study to report the presence of sVEGR-R1 in BAL fluid of patients with ARDS. As it was detected in only two patients' plasma, this suggests that sVEGF-R1 is produced locally within the lung in ARDS. This natural inhibitory role of of VEGF in protecting the lung in patients with ARDS requires further evaluation.

\section{G.D. Perkins, F. Gao}

Birmingham Heartlands Hospital, Birmingham, UK.

\section{Cigarette smoke condensate inhibits apoptosis and promotes necrosis}

Cigarette smoking is the major aetiological factor in the pathogenesis of emphysema, an inflammatory disease, which is characterised by destruction of alveolar walls thought to be as a result of alveolar epithelial and endothelial cell apoptosis. However, necrosis and not apoptosis was observed in response to cigarette smoke condensate (CSC) in alveolar epithelial cells (mean \pm SEM, control $0 \pm 0 \%$, CSC $63.65 \pm 18.1 \%$, $\mathrm{n}=3$ ), human umbilical vein endothelial cells (control $0 \pm 0 \%$, CSC 53.5 $\pm 4.14 \%, \mathrm{n}=3$ ) and Jurkat cells (control 0.17 $\pm 0.23 \%$, CSC $63.95 \pm 9.67 \%, n=3)$. In addition, CSC treatment of Jurkat T-cells resulted in inhibition of apoptosis (control $0.1 \pm 0.12 \%$, SS $96 \pm 1.38 \%, \quad$ CSC $0.22 \pm 0.26 \%$, SS/CSC $0.27 \pm 0.25 \%, n=3$ ), which could be prevented by addition of extracellular glutathione and dithiothreitol, but not mannitol or vitamin E. Mechanistic analysis of the cell death pathway, by reconstitution of an active apoptosome in cytoplasmic extracts from Jurkat cells, showed that CSC treatment inhibited caspase- 9 activation and thereby prevented activation of caspase-3, detected by Western blot analysis. Preincubation with LY294002, PD98059 or SB203580 indicated that caspase-9 inhibition was not dependent on phosphoinositide 3-kinase, mitogen-activated protein kinase kinase-1 or p38 activation. Thus, it is proposed that necrosis, not apoptosis, may be responsible for the inflammation and loss of alveolar tissue mass observed in emphysema.

\section{J. A. Wickenden*, M.C.H. Clarke ${ }^{\#}$, K. Donaldson*, W. MacNee*}

*ELEGI/Colt Research Laboratories and ${ }^{\text {\#} P h a g o c y t e ~}$ Laboratories, Medical Research Council Centre for Inflammation Research, University of Edinburgh Medical School, Edinburgh, UK.

\section{Reduced expression of $C O X-2$ results in limited induction of $P G E_{2}$ and an enhanced fibrotic response following bleomycin-induced lung injury}

Prostaglandin $(\mathrm{PG}) \mathrm{E}_{2}$ is a potent inhibitor of fibroblast proliferation and collagen production, however, levels of $\mathrm{PGE}_{2}$ are reduced in bronchoalveolar lavage fluid (BALF), and lung fibroblasts from patients with pulmonary fibrosis (PF). Limited induction of $\mathrm{PGE}_{2}$ in fibroblasts has been shown to be due to a failure to upregulate cyclooxygenase (COX)-2, the rate-limiting enzyme in $\mathrm{PGE}_{2}$ biosynthesis. To further investigate the roles of COX-2 and $\mathrm{PGE}_{2}$ in the development of $\mathrm{PF}$, the bleomycin model in mice heterozygous for COX-2 (COX-2+/-) was used compared with wildtype (WT) animals and $\mathrm{BALF} \mathrm{PGE}_{2}\left(\mathrm{pg} \cdot \mathrm{mL}^{-1}\right)$ and collagen content (mg) measured, or lung tissue for histology processed. Levels of BALF PGE 2 are shown in table 1.

Seven days following bleomycin instillation, synthesis of $\mathrm{PGE}_{2}$ is significantly reduced in COX-2+/- mice compared with WT animals, $\mathrm{p}<0.05$. BALF $\mathrm{PGE}_{2}$ production peaks at 14 days in both genotypes and is still significantly upregulated in WT mice 28 days following bleomycin. However, $\mathrm{PGE}_{2}$ synthesis returns to saline levels in COX-2+/- mice at day 28. Reduced levels of $\mathrm{PGE}_{2}$ in $\mathrm{COX}-2+/-$ mice correlated with Table 1.- Levels of bronchoalveolar lavage fluid
prostaglandin $E_{2}$ of

\begin{tabular}{lccccc}
\hline Days $^{\#}$ & \multicolumn{2}{c}{ Saline } & & \multicolumn{2}{c}{ Bleomycin } \\
\cline { 2 - 3 } \cline { 5 - 6 } & WT & COX-2+/- & WT & COX-2+/- \\
\hline 3 & & & & & \\
\hline 7 & $59.0 \pm 29.8$ & $43.9 \pm 2.0$ & & $283.3 \pm 104.0$ & $344.6 \pm 121.6$ \\
14 & $233.3 \pm 64.6$ & $58.9 \pm 10.7$ & & $1234.0 \pm 407.2$ & $321.8 \pm 72.2$ \\
28 & $177.2 \pm 70.3$ & $165.9 \pm 59.0$ & & $535.1 \pm 166.6$ & $221.4 \pm 49.2$ \\
\hline
\end{tabular}

Data are presented as mean $\pm \mathrm{SEM} \mathrm{pg} \cdot \mathrm{mL}^{-1}$. WT: wildtype; COX: cyclooxygenase. ${ }^{\#}$ : following instillation. 
an approximate $44 \%$ increase in lung collagen content compared with WT mice after 28 days (WT 2.6 \pm 0.22 , COX-2+/$3.77 \pm 0.12 ; \mathrm{p}<0.001)$. Histological analysis also showed greater staining for matrix proteins in COX-2+/- mice compared with WT mice. Together, these data suggest that reduced expression of COX-2 leads to limited production of $\mathrm{PGE}_{2}$ and an enhanced fibrotic response to lung injury. Therefore, upregulation of COX-2 expression in the lungs of patients with PF may represent a novel therapeutic strategy for this condition.

\section{R.J. Hodges, R.G. Jenkins, S.E. Bottoms, G.J. Laurent, R.J. McAnulty}

Centre for Respiratory Research, University College, London, UK.

\section{Early growth response genes are preferentially transactivated in stage IIIIII sarcoidosis}

Sarcoidosis is a disease with an unknown pathogenetic mechanism and growth factors are thought to play a major role in its pathogenesis. They may mediate differences between phenotypes, i.e. self-limited disease versus progressive fibroproliferative lung disease. The aim of the present study was to investigate the expression pattern of growth factors in different sarcoidosis phenotypes using gene expression array technology.

A comprehensive genomic analysis was performed applying

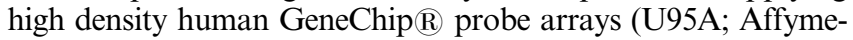
trix, Santa Clara, CA, USA) to blood of 12 patients with sarcoidosis (stage I $n=7$, stage II/III $n=5$ ) and 12 matched healthy controls. Two hundred and sixty growth-related genes were identified and analysed. Target validation was performed using immunohisto- and cytochemistry in tissue microarrays.

Of the 260 growth genes, $193(74 \%)$ were expressed and 39 $(15 \%)$ were dysregulated in sarcoidosis. Of these genes, 19 were up- and 20 genes were downregulated. In patients with progressive fibroproliferative lung involvement, early growth response (EGR) genes 1, 2, 3, 4, and $\alpha$ were preferentially upregulated. Immunohistochemistry using tissue microarrays of normal human organs demonstrated EGR expression uniquely in thymus (cortex) and lymph nodes (germinal centre). Lung biopsy specimens of sarcoidosis patients confirmed EGR positivity in granulomas, some (myo)fibroblasts, lymphocytes and macrophages.

In conclusion, patients with sarcoidosis stage II/III show an upregulation of EGR genes. These data suggest that EGR genes play an important role in the pathogenesis of fibroproliferation in sarcoidosis. Gene Chip $\mathbb{R}$ technology may help to stratify sarcoidosis patients according to prognosis.

M.H. Brutsche, K. Laule-Kilian, E. Eryüksel, R. Rutherford, M. Bihl, L. Joos, J. Kehren, F. Staedtler, M. Tamm, L. Bubendorf

Pulmonology Dept, Internal Medicine, University Hospital Basel, and Novartis Pharma AG, Preclinical Safety, Toxicology/Pathology, Pharmacogenomics, Basel, Switzerland. Dept of Respiratory Medicine, University Hospital Galway, Galway, Ireland.

Neutrophils contribute to the phagocytosis of apoptotic cells and cell debris during resolution of a lung neutrophilic inflammation

Cell apoptosis and engulfment of apoptotic cells by macrophages is a key mechanism for silent removal of peripheral lung neutrophils. However, if the phagocytic capacity is overwhelmed apoptotic cells may die violently through secondary necrosis. Hence, in this situation it is possible that nonmacrophage cells may also assist in the engulfment of apoptotic cells and cell debris. This study explores the fate of neutrophils in tissue areas where the phagocytotic capacity of macrophages is insufficient.

$\mathrm{Balb} / \mathrm{C}$ mice were given lipopolysaccharide (LPS; Escherichia coli $10 \mu \mathrm{g}$ ) by intranasal administration. The experiment was terminated at $4,12,24,36,48,60$ and $72 \mathrm{~h}$ post-LPS exposure when bronchoalveolar lavage (BAL) and tissue samples were collected.

BAL neutrophils increased significantly by $4 \mathrm{~h}$, peaked at $36 \mathrm{~h}$, and returned to control levels by $72 \mathrm{~h}(\mathrm{p}<0.001-0.05)$. In lung sections, TUNEL-positive cells, which were mainly distributed in the air spaces, were significantly increased $12 \mathrm{~h}$ and onwards $(\mathrm{p}<0.001-0.01)$. BAL macrophages containing DNA-positive (Hoechst 33342) phagosomes were significantly increased from $36 \mathrm{~h}$ and onwards $(\mathrm{p}<0.01-0.05)$. At these time points TUNEL-positive cell debris was evident in neutrophil-rich lung areas. Detailed transmission electron microscopic analysis confirmed the rich occurrence of apoptotic neutrophils and their engulfment by macrophages. In addition, neutrophils with phagosomes containing condensed cell nuclei and cell debris were present in areas rich in secondary necrosis and extracellular cell debris.

This study suggests that high numbers of apoptotic cells may exceed the phagocytic capacity of macrophages resulting in secondary necrosis and local areas with aggravated inflammation. Interestingly, in such areas viable neutrophils may also significantly contribute to the engulfment of apoptotic cells and cell debris. The data further indicate that resolution of high numbers of inflammatory cells involves a delicate balance between apoptosis and potentially pathogenic shapes of death. Hence, caution is required for treatment strategies involving pro-apoptotic drugs.

\section{J.S. Erjefält, L. Uller, K. Rydell, C.G.A. Persson}

Dept of Physiological Sciences, Lund University Hospital, Lund, Sweden.

Retinoic acid depletion downregulates sonic hedgehog in differentiated human bronchial epithelial cells in vitro

The retinoic acid (RA) system is a key pathway in pattern formation in the mammalian lung. Recent studies have suggested that RA may induce realveolarisation in damaged rodent airways. In addition, patients with chronic obstructive pulmonary disease show decreased levels of RA in their serum. The authors studied how RA and cigarette smoke extract (CSE) modulate the expression of three pattern-related genes, sonic hedgehog (SHH), hepatocyte nuclear factor-3/Forkhead homologue-4 (HFH-4) and $10 \mathrm{kD}$ Clara cell secreted protein (CCSP), in a model system for redifferentiation of normal human bronchial epithelial (NHBE) cells.

Air-liquid interface (ALI) cultures of NHBE cells were allowed to differentiate for up to 60 days. Cultures of 21 days were maintained for $54 \mathrm{~h}$ in minimal medium $(1 \%$ ITS $/ 0.1 \%$ bovine serum albumin in BEBM) with or without $15 \mathrm{ng} \cdot \mathrm{mL}^{-1}$ RA. Separate cultures were exposed to apical CSE (5-40\%) during the last $30 \mathrm{~h}$ in minimal medium. Gene expression was monitored by Taqman analysis.

While undifferentiated NHBE cells expressed very low levels of mRNA for all genes, differentiation induced expression of all genes. This was accompanied by the appearance of ciliated cells and mucus-producing goblet cells. Depletion of 
RA downregulated SHH significantly $(\mathrm{p}<0.001)$, while the expression of HFH-4 and CCSP remained unchanged. In addition CSE exposure downregulated all genes in a dosedependent fashion up to a concentration of $20 \%$ CSE.

Differentiation of NHBE cells in ALI cultures induces genes involved in developmental signalling systems. While all genes are affected by CSE, only SHH expression seems to be regulated by RA, which is in line with data from rat lung explants. The main source of RA in vivo are the subepithelial fibroblasts, highlighting the regulatory function of the epithelial mesenchymal trophic unit, while the downregulation of the investigated genes by CSE may suggest an impaired interaction in smoke-related disease.

S. Möller, C. Zackrisson, K. Kristensson, E. Wieslander Discovery Biosciences, AstraZeneca R\&D Lund, Lund, Sweden.

\section{Critical levels of GSH are needed for differentiation in skeletal muscle cells $\mathrm{C} 2 \mathrm{C12}$}

Human skeletal muscle atrophy or cachexia are associated with a variety of serious clinical conditions including some inflammatory disorders, sepsis and chronic obstructive pulmonary disease (COPD). Many studies have implicated the induction of oxidative stress in muscle in these largely catabolic events, and this phenomenon is associated with the loss of glutathione (GSH).

An abnormal GSH regulation in muscle of COPD patients correlating with high levels of tumour necrosis factor (TNF)$\alpha$ plasma levels was previously demonstrated. A recent study shows a decrease in GSH during myogenic differentiation of $\mathrm{C} 2 \mathrm{C} 12$ cells elicited by TNF- $\alpha$. Using myoblasts and myotubes from $\mathrm{C} 2 \mathrm{C} 12$ cells, the role of GSH during differentiation process was studied. Myoblasts at confluence (day 0) formed myotubes after serum restriction, with an $80 \%$ of myotubes at day 7 .

Total GSH levels during differentiation were similar in myoblasts and myotubes from days 4-7 $\left(25 \pm 6 \mathrm{nmol} \cdot \mathrm{mg}\right.$ protein $\left.^{-1}\right)$, while during the first 2 days these levels significantly increased $\left(40 \pm 3 \mathrm{nmol} \cdot \mathrm{mg}\right.$ protein $\left.{ }^{-1}, \mathrm{p}<0.05\right)$, accompanied with an induction of the $\gamma$-glutamylcysteine synthetase activity $(3.9 \pm 0.1$ and $2.6 \pm 0.01 \mathrm{nmol} \cdot \mathrm{min}^{-1} \cdot \mathrm{mg}$ protein ${ }^{-1}$, days 1 and 0 , respectively; $\mathrm{p}<0.05$ ). As these findings suggested that GSH induction contributes to differentiation, GSH levels were first depleted with diethyl maleate (D) and buthionine sulfoximine (B) for $24 \mathrm{~h}, 1$ day after serum restriction. Seven days later, GSH levels were only $33 \%$ of the control levels $(15.5 \pm 3$ and $4.9 \pm 4 \mathrm{nmol} \cdot \mathrm{mg}$ protein $^{-1}$, control and treated, respectively, $\mathrm{p}<0.05$ ). This treatment did not cause toxicity as assessed by lactate dehydrogenase release, but resulted in a $20 \%$ reduction in total protein content of myosin and in creatine kinase (CK) activity (1.15 \pm 0.02 and $0.86 \pm 0.09 \mathrm{U} \cdot \mathrm{mg}$ protei $^{-1}$, control and treated, respectively; $\mathrm{p}<0.05$ ). To restore GSH levels, cells were incubated with GSH ethyl ester for 24 or 48 h, 1 day after the D/B treatment. At day 7, GSH levels were completely restored to control levels and accompanied with a normalisation of CK activity and the content of major histocompatibilty complex.

These results indicate that an optimal GSH content is necessary for differentiation of myoblasts into myotubes, which can be of relevance as a strategy to restore muscle damage in catabolic events associated with COPD.

\section{E. Ardite*, R. Rabinovich*, J.A. Barbera*, J. Roca*, J.C. Fernandez-Checa ${ }^{\#}$}

*Depts of Pulmonary Medicine and ${ }^{\#}$ Liver Unit, Hospital Clinic, University of Barcelona, Barcelona, Spain.
Hypersensitivity of bronchopulmonary C-neurones induced by airway mucosal inflammation

Stimulation of vagal bronchopulmonary C-fibres induces bronchoconstriction and hypersecretion of mucus, and enhances the sensitivity of cough reflex. Recent studies in the laboratory have shown that the excitability of these afferents is elevated in several experimental conditions involving acute injury and inflammation of airway mucosa. Although the underlying mechanisms are not yet fully understood, endogenous cyclooxygenase metabolites are believed to play a part because the C-fibre hypersensitivity was attenuated by pretreatment with indomethacin in some of these experiments. Indeed, recently it was found that prostaglandin $(\mathrm{PG}) \mathrm{E}_{2}$ alone can generate a pronounced sensitising effect on pulmonary $\mathrm{C}$-fibres in anaesthetised rats.

To investigate the cellular mechanisms involved in the $\mathrm{PGE}_{2}$-induced hypersensitivity of these afferents, the membrane excitability of capsaicin-sensitive nodose and jugular ganglion neurones in primary culture were measured using the whole-cell perforated patch-clamp recording technique; the neurones innervating the lungs were identified by retrograde labelling with a fluorescent dye (DiI) in young SpragueDawley rats. $\mathrm{PGE}_{2}\left(10^{-6}\right.$ or $\left.10^{-7} \mathrm{M}\right)$ perfusion markedly and reversibly increased both the magnitude of inward current (in voltage-clamp mode) and the number of action potentials (in current-clamp mode) evoked by capsaicin $\left(10^{-7} \mathrm{M}, 4 \mathrm{~s}\right)$ in the same neurones.

The current/voltage curves obtained by applying depolarising voltage steps also showed that $\mathrm{PGE}_{2}$ perfusion significantly increased the magnitude of peak inward current, did not change the reversal potential, and shifted the activation curve to the left (hyperpolarisation). Furthermore, the $\mathrm{PGE}_{2}$-induced hypersensitivity of these neurones could be closely mimicked by perfusion with butaprost $\left(2 \times 10^{-7} \mathrm{M}\right)$, a selective agonist of the $\mathrm{EP}_{2}$ prostanoid receptor. In addition, results obtained in a parallel study suggest that the $\mathrm{PGE}_{2}-$ induced potentiation of calcium influxes evoked by various chemical stimuli in cultured pulmonary C-neurones is mediated through the cyclic adenosine monophosphate/protein kinase A transduction cascade initiated by activation of the $\mathrm{EP}_{2}$ receptor.

To conclude, $\mathrm{PGE}_{2}$ enhances the sensitivity of pulmonary nodose and jugular capsaicin-sensitive neurones to both chemical and electrical stimulations, and activation of the $\mathrm{EP}_{2}$ receptor is probably involved.

\section{L-Y. Lee, Q. Gu, K. Kwong}

Dept of Physiology, University of Kentucky Medical Center, Lexington, USA.

Airway neutrophilic inflammation decreases after exercisebased rehabilitation in COPD patients

Exercise-based rehabilitation in chronic obstructive pulmonary disease (COPD) patients is known to improve functional capacity and decrease dyspnoea, but the possible contribution of airway inflammatory cells to these changes is unknown. Airway cells were studied in induced sputum samples collected under resting conditions in seven COPD patients before and after a 4-week rehabilitation programme based on endurance training.

The mean \pm SD age of the sample was $66.4 \pm 4.5$ yrs, FEV1 was $1.61 \pm 0.28 \mathrm{~L}(55 \pm 13 \%$ predicted $), \mathrm{FVC}$ was $3.22 \pm 0.39 \mathrm{~L}$ $(90 \pm 13 \%$ pred), resting arterial oxygen tension and arterial carbon dioxide tension were $9.6 \pm 1.5$ and $5.3 \pm 0.4 \mathrm{kPa}$, 
respectively ( $72 \pm 11$ and $40 \pm 3 \mathrm{mmHg}$, respectively). All patients were on inhaled bronchodilator plus steroid treatment during the entire duration of the study. After rehabilitation, peak oxygen uptake per $\mathrm{kg}$ increased from $16.9 \pm 3.6$ to $20.3 \pm 4.3 \mathrm{~mL} \cdot \mathrm{min}^{-1}$, peak minute ventilation increased from $46 \pm 7$ to $56 \pm 9 \mathrm{~L} \cdot \mathrm{min}^{-1}$, while dyspnoea index (Borg scale) decreased from $7.4 \pm 2.6$ to $5.0 \pm 3.2$.

Total corrected cell counts in induced sputum tended to decrease (prerehabilitation $2.296 \pm 2.064 \times 10^{6}$ cells $\cdot \mathrm{mL}^{-1}$, postrehabilitation $1.303 \pm 1.687 \times 10^{6}$ cells $\left.\cdot \mathrm{mL}^{-1}\right)$, with significantly decreased neutrophil (pre $76 \pm 9 \%$, post $67 \pm 8 \% ; \mathrm{p}<0.05$ ) and increased macrophage (pre $19 \pm 7 \%$, post $25 \pm 8 \% ; \mathrm{p}<0.05$ paired t-test) differential counts. All other cell types were unaffected.

These preliminary data suggest a positive effect of exercisebased rehabilitation on airway inflammatory cells in COPD, supporting their possible involvement in modulating the dyspnoea sensation in these patients.

M. R. Bonsignore*, A. Satta ${ }^{\#}$, P. Palange ${ }^{\star}$, B. Chizzoni ${ }^{\#}$, A.M. Vignola *, M. Neri ${ }^{\#}$, V. Bellia*, G. Bonsignore ${ }^{+}$ *Institute of Medicine and Pneumology, University of Palermo, "Fondazione S. Maugeri IRCCS, Tradate (VA), `University La Sapienza, Rome, and ${ }^{+}$IBIM-CNR, Palermo, Italy.

\section{Cigarette smoke extract inhibits angiogenesis of pulmonary artery endothelial cells: role of calpain and eNOS}

Angiogenesis is an integral part of both the pulmonary inflammatory response to chronic exposure to cigarette smoke and the vascular remodelling associated with cigarette smoke-induced chronic obstructive lung disease (COLD).

In the present study, the effect of cigarette smoke extract (CSE) on angiogenesis of pulmonary artery endothelial cells (PAEC) was evaluated. The role of calpain and endothelial nitric oxide synthase (eNOS) were focused upon because CSE has previously been reported to decrease eNOS expression and eNOS activity is regulated, in part, by the calciumdependent, neutral endopeptidase calpain. PAEC were incubated with and without (control) CSE (7.5\%) in the presence and absence of calpain inhibitor I, antisense ODN of calpastatin, the major endogenous calpain inhibitor, $\mathrm{N}$ nitro-L-arginine methyl ester HCI (L-NAME), an eNOS inhibitor, and $S$-nitroso- $N$-acetyl-D,L-penicillamine (SNAP), an NO donor, after which wound repair, tube formation on matrigel, cell migration in a Boyden chamber, and cell proliferation were assayed.

Incubation of PAEC with CSE for $16 \mathrm{~h}$ resulted in $25-35 \%$ decreases in wound repair $(p<0.05)$, tube formation $(\mathrm{p}<0.05)$, and proliferation $(\mathrm{p}<0.05)$. However, in the presence of calpain inhibitor I $(10 \mu \mathrm{M})$ or L-NAME $(5 \mathrm{mM})$, incubation of PAEC with $7.5 \%$ CSE caused decreases of $50-70 \%$ in wound repair, tube formation, cell migration, and proliferation $(\mathrm{p}<0.05$ for all versus no inhibitor). In contrast, in the presence of antisense ODN of calpastatin $\left(0.16 \mathrm{ng} \cdot \mu \mathrm{L}^{-1}\right)$, incubation of PAEC with $7.5 \% \mathrm{CSE}$ caused decreases of only $8-12 \%$ in wound repair, tube formation, migration and proliferation. Moreover, incubation of PAEC with SNAP $(10 \mu \mathrm{M})$ prevented CSE-induced inhibition of wound repair and tube formation.

These results suggest that CSE attenuates angiogenesis of PAEC and that the mechanism involves inhibition of calpain and eNOS. Impaired angiogenesis may impede the inflammatory response in the lungs of cigarette smokers and contribute to the altered vascular remodelling observed in the lungs of patients with cigarette-related COLD.

\section{W. Cao, Y. Su, E. Block}

University of Florida and Gainesville, VA Medical Center, Gainesville, FL, USA.

TNF- $\alpha$ converting enzyme: altered regulation of a key regulator of $T N F-\alpha$ activity in inflammatory lung disease

Tumour necrosis factor (TNF)- $\alpha$ converting enzyme (TACE) cleaves membrane-associated TNF- $\alpha$ (mTNF) at the Ala-76-Val-77 site to yield the $26 \mathrm{kD}$ soluble product. Consequently, TACE activity is a key step in the regulation of TNF- $\alpha$ biological activity. Regulation of cleavage by TACE in human cells is poorly understood and, in the context of lung inflammation, there have been no studies relating to the alveolar macrophage (AM).

AMs were isolated from normal subjects and subjects with idiopathic pulmonary fibrosis (IPF) or pulmonary sarcoidosis by bronchoalveolar lavage in order to evaluate: 1) basal levels of TACE protein expression; 2) constitutive catalytic activity of TACE; and 3) modification of TACE expression by the inflammatory mediators. The relationship between TACE expression and activity relative to $\mathrm{mTNF}$ surface expression was also examined. Using flow cytometry, constitutive TACE expression was detected on the surface of all AMs, but this expression was higher in IPF and sarcoidosis subjects relative to normal subjects (median fluorescent intensities 3.50, 5.15 and 0.30 , respectively; $\mathrm{p}=0.03$ and 0.006 ).

TACE catalytic activity as assessed by cleavage of glutathione- $S$-transferase-proTNF was also significantly elevated in IPF and sarcoidosis subjects relative to normal subjects ( $\mathrm{p}=0.002$ and $\mathrm{p}=0.05$, respectively). Catalytic activity positively correlated with TACE protein expression $(\mathrm{p}=0.04)$ and negatively correlated with mTNF expression $(\mathrm{p}=0.05)$ suggesting that TACE detectable by flow cytometry reflects functional activity. Addition of inflammatory mediators to AMs from normal subjects revealed that TACE was significantly upregulated by lipopolysaccharide $(\mathrm{p}=0.02)$ and interferon- $\gamma(\mathrm{p}=0.02)$ and downregulated by interleukin-10 $(p=0.02)$. By contrast, TACE expression on AMs from subjects with IPF or sarcoidosis was not significantly altered by any stimuli. These data indicate that regulation of TACE is abnormal in IPF and sarcoidosis and may contribute to the increased levels of TNF- $\alpha$ activity associated with inflammatory lung disease.

\section{Armstrong, S.I.H. Godinho, K.M. Uppington, A.B. Millar}

Lung Research Group, University of Bristol, Division of Medicine, Bristol, UK.

\section{Proliferation and inflammation after allergen exposure in bronchial epithelium of atopic asthmatics}

The mechanisms that regulate epithelial integrity and repair in asthma are poorly understood. It was hypothesised that allergen exposure could alter epithelial inflammation, damage and proliferation in atopic asthma. Epithelial cell infiltration, shedding, expression of the proliferation marker Ki-67 and the epithelial cell-cell adhesion molecules Ep-CAM and Ecadherin were studied in bronchial biopsies of 10 atopic mild asthmatics $48 \mathrm{~h}$ after experimental diluent (D) and 
allergen (A) challenge in a crossover design. Ki-67+, eosinophil/EG-2+, CD4+ and CD8+ cells were quantified by image analysis in bronchial epithelium, and adhesion molecules were analysed semiquantitatively.

Epithelial shedding (per cent not intact epithelium) was not altered by A (D $88.1 \pm 3.1 \%$ versus A $89.2 \pm 3.7 \%$; $=0.63$ ). The numbers of $\mathrm{Ki}-67+$ epithelial (D $10.2 \pm 0.2$ versus $\mathrm{A}$ $19.9 \pm 0.3$ cells $\left.\cdot \mathrm{mm}^{-3} ; \mathrm{p}=0.03\right), \mathrm{EG}-2+(\mathrm{D} 4.3 \pm 0.5$ versus $\mathrm{A}$ $27 \pm 0.3$ cells $\left.\cdot \mathrm{mm}^{-3} ; \mathrm{p}=0.04\right)$ and $\mathrm{CD} 4+$ cells $(\mathrm{D} 1.7 \pm 1.2$ versus A $12.3 \pm 0.6$ cells $\cdot \mathrm{mm}^{-3} ; \mathrm{p}=0.04$ ) were significantly increased after A, whilst CD8+ numbers were not significantly changed ( $>0.05)$. E-cadherin and Ep-CAM epithelial staining showed a similar intensity after $\mathrm{D}$ and $\mathrm{A}(\mathrm{p}>0.05)$.

A positive correlation between EG-2+ and Ki-67+ cells in epithelium ( $\mathrm{r}$ 0.63, p=0.02) was found. This study indicates that allergen challenge increases epithelial proliferation in conjunction with inflammation at 2 days after exposure.

F.L.M. Ricciardolo*,\#, A. Di Stefano ${ }^{\star}$, J.H.J.M. van Krieken $^{+}$, J.K. Sont ${ }^{\S}$, A. van Schadewijk*, K.F. Rabe*, C.F. Donner ${ }^{*}$ P.S. Hiemstra*, P.J. Sterk*, T. Mauad* *Dept of Pulmonology and ${ }^{\S}$ Dept of Medical DecisionMaking, Leiden University Medical Centre, and ${ }^{+}$Dept of Pathology, University Medical Center St Radboud, Nijmegen, The Netherlands. ${ }^{\#}$ Division of Pulmonology, Ospedali Riuniti, Bergamo, and ${ }^{\top} \mathrm{S}$. Maugeri Foundation, Verona, Italy.

\section{Neutrophil apoptosis and sputum microbiology in $C F$}

Chronic endobronchial inflammation and bacterial infection are the main causes of morbidity and mortality in cystic fibrosis (CF). Inflammation is characterised by excessive neutrophil influx. Pseudomonas aeruginosa infection is associated with an exaggerated inflammatory response and colonisation with Burkholderia cepacia is often accompanied by progressive pulmonary deterioration. Apoptosis of inflammatory cells is essential for the resolution of inflammation. It was hypothesised that the number of neutrophils undergoing apoptosis/necrosis would alter with the causative infectious agent in CF lungs. The study aimed to assess the relationship between levels of neutrophil cell death and sputum microbiology in matched clinically stable $\mathrm{CF}$ patients.

In total 34 patients were recruited; eight (three males) with no Gram-negative infection, 10 (four male) colonised with $P$. aeruginosa, 10 (four male) with $B$. cepacia infection and five (three male) with other Gram-negative infections such as Stenotrophomonas maltophilia. Sputum was induced as described previously. Apoptosis was investigated by staining sputum cells with propidium iodide (PI) and annexin V (AV), and subsequent flow cytometric analysis. Nonparametric statistical analyses were used.

The percentage of necrotic granulocytes (AV-PI+) was significantly higher in the $P$. aeruginosa group $(17.1 \pm 2.5 \%$, $\mathrm{p}=0.03)$ and the $B$. cepacia group $(13.9 \pm 1.2 \%, \mathrm{p}=0.002)$ compared with those with no Gram-negative infection $(7.1 \pm 1.4 \%)$. B. cepacia patients also had a significantly higher percentage secondary necrotic cells $(\mathrm{AV}+\mathrm{PI}+)$ than those with no Gram-negative infection $(12.5 \pm 2.3 \%$, $5.8 \pm 1.5 \%, \mathrm{p}=0.04)$, whilst those with no Gram-negative infection had a significantly higher percentage of viable cells (AV-PI- 79.2 $\pm 4.3 \%$ ) than the B. cepacia and $P$. aeruginosa groups $(60.2 \pm 4.3 \%, \mathrm{p}=0.006 ; 62 \pm 5.6 \%, \mathrm{p}=0.03$, respectively).

These results indicate that neutrophil cell death is associated with the type of organism colonising the CF lung. The greater number of granulocytes in necrotic pathways from patients infected with $P$. aeruginosa or $B$. cepacia suggests that this may be a mechanism of greater inflammation and subsequent lung injury.

\section{A.P. Watt*, J. Courtney*, J. Moore* , J.S. Elborn*, M. Ennis* \\ *Respiratory Research Group, Centre for Infection, Inflam- mation and Repair, The Queen's University of Belfast and \#Dept of Bacteriology, Belfast City Hospital, Belfast, UK.}

Assessment of ventilation defects in emphysematous rat lung using hyperpolarised ${ }^{3} \mathrm{He}-\mathrm{MRI}$

The measurement of regional pulmonary ventilation is of major importance in studies of lung physiology and investigations of lung disease. By utilising ${ }^{3} \mathrm{He}$-magnetic resonance imaging (MRI), the authors recently developed a method for quantitative measurement of regional pulmonary ventilation with high spatial and temporal resolution in small animals. The method exploits the build-up of the signal intensity after a variable number of ${ }^{3} \mathrm{He}$ breaths (usually $1-4$ ). The regional ventilation value is calculated on a voxel-by-voxel basis and is expressed as the fraction of gas exchanged per breath. The aim of this study was to measure regional ventilation in a model of early stage pulmonary emphysema in rats. Four weeks prior to imaging, the rats were pretreated with porcine elastase (75 U per $100 \mathrm{~g}$ body weight) or saline (controls) intratracheally into the left lung. On the day of experiment, the rats were anaesthetised, tracheotomised, paralysed and placed in supine position in the MR scanner. Air or ${ }^{3} \mathrm{He}$ were delivered to the rats via an MR-compatible ventilator. Coronal ${ }^{3} \mathrm{He}$ ventilation maps of the control lungs showed ventilation values close to 1.0 in the trachea and the major airways. In the lung parenchyma, values of $0.6-0.8$ were observed in regions adjacent to the hilum, whereas lower values $(0.2-0.5)$ was measured in peripheral regions. No ventilation differences were found between left and right lungs of the control animals. In the elastase-treated animals, however, the mean ventilation values of both peripheral and central regions of the left lung were significantly decreased compared with the right lung $(15.2 \%$ and $13.5 \%$ reduction, respectively; $\mathrm{p}<0.01) .{ }^{3} \mathrm{He}-\mathrm{MRI}$ may provide new opportunities to determine ventilation defects in experimental models of emphysema. The method may also open novel possibilities for detailed evaluation of regional ventilation after drug treatment.

G. Pettersson*, G. Hansson*, P. Magnusson*, J.S. Erjefält $^{\#}$, I. Erjefält*, S. Månsson ${ }^{\star}$

*Amersham Health R\&D AB, and "Dept of Experimental Research, Malmö University Hospital, Malmö, and ${ }^{\#}$ Dept of Physiological Sciences, Lund University, Lund, Sweden.

Asthma-like symptoms during work in swine confinement buildings are associated with a reduced acute immune response

Respiratory diseases due to exposure to organic dust are a major occupational health problem. Eight persons (representing $2.4 \%$ of the studied population) who had in an earlier study developed asthma-like work-related respiratory symptoms (persistent cough, wheeze, tightness in the chest) in swine confinement units, and eight persons who tolerated this environment (controls) were selected in order to study 
the differentiated immune response in the two groups. One-half of each group smoked. Cases and matched controls were studied with bronchoscopy, lung function measurements and blood samples at baseline, and after a 3-h exposure in a representative swine confinement building (SCB). Compared with controls, cases had a significantly reduced diffusion capacity $24 \mathrm{~h}$ past exposure start $(10 \%, \mathrm{p}=0.001)$ without appreciable changes in total lung or vital capacity, lowered serum interleukin (IL)-1 $\beta$ at baseline $(0.082$ versus $\left.0.181 \mathrm{pg} \cdot \mathrm{mL}^{-1}, \mathrm{p}=0.047\right)$ and during exposure $(\mathrm{p}=0.048)$, reduced bronchoalveolar lavage IL-1 $\beta$ after exposure $(\mathrm{p}=0.010)$, increased serum IL- $8(\mathrm{p}=0.014)$, upregulation of CD106 on blood monocytes $(\mathrm{p}=0.046)$ and plasma hyaluronan levels $(\mathrm{p}=0.010)$ during the $24 \mathrm{~h}$ following exposure. The inability of cases to mount a sufficient acute immune response may in the long term lead to development of asthma-like symptoms.

H.J. Hoffmann, M. Iversen, T. Sigsgaard, Ø. Omland, H. Takai, L. Bjermer, E. Bonefeldt-Jørgensen, C. Oxvig, J. Seedorf, R. Dahl

Dept of Pulmonary Medicine, and Institute of Environmental Medicine, University of Aarhus, Aarhus, Denmark.

\section{Recombinant SP-D reduces lung inflammation by promoting clearance of apoptotic alveolar macrophages in mice developing pulmonary emphysema}

Surfactant protein (SP)-D deficiency in mice causes chronic lung inflammation characterised by an excess of alveolar macrophages (AM), hyperplastic type-II cells, an accumulation of surfactant phospholipids and the development of pulmonary emphysema. The development of emphysema has been linked to high numbers of apoptotic AM in the bronchoalveolar lavage (BAL) of smokers. It was hypothesised that delayed clearance of apoptotic cells in SP-D-deficient mice contributed to the accumulation of AM and chronic lung inflammation. Using Annexin $\mathrm{V}$ and propidium iodide as markers for apoptosis and necrosis, respectively, SP-D-deficient mice have a 5-10-fold increase in the number of apoptotic and necrotic AM in the lungs. These findings were confirmed on TUNEL assay by incorporation of deoxyuridine triphosphate-fluoroscein isothiocyanate and direct visualisation by confocal microscopy. Administration of recombinant SP-D to SP-D-knockout mice reduced the number of apoptotic and necrotic AM and partially corrected the accumulation of surfactant lipids in the alveolar space. The overall number of AM recovered after BAL in recombinant SP-D-treated knockout mice was $50 \%$ lower compared with controls $(\mathrm{p}<0.05, \mathrm{n}=4-6$ mice in each group) after 3 weeks of treatment. Surfactant phospholipid levels were significantly lower after 6 weeks of exogenous recombinant SP-D replacement $(\mathrm{p}<0.05)$. Using a ribonuclease protection assay for chemokines expressed in total lung RNA, monocyte chemoattractant protein-1 and macrophage inflammatory protein- $1 \alpha$ mRNAs were significantly raised in SP-D-knockout mice $(\mathrm{p}<0.01)$ compared with wildtype, but reduced after treatment with recombinant SP-D $(\mathrm{p}<0.05)$, consistent with decreased influx of AM into the lungs. The same recombinant SP-D binds preferentially to apoptotic and necrotic AM in vitro, consistent with a role for SP-D in controlling lung inflammation by targeting apoptotic cells for clearance from the lungs and by decreasing AM recruitment into the alveolar space. Therapeutic application of recombinant SP-D may offer a novel strategy in macrophage-mediated lung inflammation.

H.W. Clark*, N. Palaniyar*, P. Strong*, J. Edmondson*, S. Hawgood ${ }^{\#}$, K.B.M. Reid*

MRC Immunochemistry Unit, Dept of Biochemistry, University of Oxford, Oxford, UK. ${ }^{\#}$ Cardiovascular Research Institute, University of California, San Francisco, CA, USA.

Potential role for CDId restricted T-cells in the immunopathology of sarcoidosis

CD1d-restricted NKT cells (cNKT) are a distinctive subset of T-lymphocytes that, upon activation by a lipid ligand, produce large amounts of both T-helper cell (Th) type-1 and Th2 cytokines. They are thought to have an immunoregulatory role. This study investigated whether these cells could be involved in the immunopathology of granulomatous inflammatory lung disease using sarcoidosis as the disease model.

CD1d-lipid-tetramers and fluorescence-activated cell sorter staining of the invariant $\mathrm{V} \alpha 24 \mathrm{~V} \beta 11 \mathrm{~T}$-cell receptors were generated and utilised to specifically examine the frequency of cNKT in the lungs and peripheral blood of sarcoid patients. This showed a distinct reduction of cNKT in the peripheral blood of all 21 sarcoid patients compared with normal controls, regardless of disease activity (median frequency as per cent of lymphocytes 0.02 versus $0.19 ; \mathrm{p}<0.001$ ). This was not due to reduced CD1d expression on dendritic cells or monocytes. In the lungs (bronchoalveolar lavage), two of six sarcoid patients showed increased staining for cNKT, in the presence of extensive interferon- $\gamma$ production by CD4 T-cells.

In order to examine the effect of these cells on other lymphocytes, cNKT clones were derived from two normal donors and the proliferation of peripheral blood mononuclear cells co-cultured with these clones was examined. Specific activation of these clones causes an early increase in proliferation of the co-cultured peripheral blood mononuclear cells and enhances the recall response of T-cells. To determine if the ligand for cNKT is found in Kveim reagent, glycolipids were purified from Kveim reagent and examined if they activated the cNKT clones. This was negative, suggesting that activation of cNKT is likely to be independent of the initial trigger of this disease.

To conclude, the study shows that cNKT is deficient in the peripheral blood of sarcoidosis, possibly due to homing of these cells to the lungs after the initial trigger of the disease. One consequence of its presence in the lungs could be augmentation of the inflammatory response at this site.

\section{L.P. Ho, G.S. Besra, V. Cerundolo, A.J. McMichael}

Medical Research Council Human Immunology Unit, Institute of Molecular Medicine, and Centre for Respiratory Medicine, Churchill Hospital, Oxford, UK.

Exon 22 A3650G, intron 27 T520C and exon 33 C5507G polymorphisms of complement receptor 1 gene are associated with IPF

Erythrocyte (E) complement receptor 1 (CR1) is a membrane protein mediating the transport of immune complexes (ICs) to phagocytes. Three polymorphic sites of the CR 1 gene (exon $22 \mathrm{~A} 3650 \mathrm{G}$, intron $27 \mathrm{~T} 520 \mathrm{C}$ and exon $33 \mathrm{C} 5507 \mathrm{G}$ ) are related to $\mathrm{E}$ surface density of $\mathrm{CR} 1$, in turn related to the rate of IC clearance. The authors previously demonstrated 
an association between sarcoidosis and CR 1 genotypes coding for reduced CR1/E ratio. Since idiopathic pulmonary fibrosis (IPF) shares with sarcoidosis the hypothesis of putative triggering exogenous factor(s), it was hypothesised that a late clearance of ICs may also be involved in the pathogenesis of IPF. To this aim, the three CR1 polymorphisms were analysed by polymerase chain reaction-restriction fragment length polymorphism and direct sequencing in a group of 73 patients affected by IPF, as well as in 166 sex-, age-, and ethnicity-matched controls was performed. Evidence was found that the intron 27 polymorphism (previously referred to as intron 27 HindIII RFLP) is a $\mathrm{T} \rightarrow \mathrm{C}$ substitution $\mathrm{nt}$ 520 (GeneBank access number AY 158532). The three polymorphisms were in strong linkage disequilibrium. The GG genotype for the $\mathrm{C}_{5507} \mathrm{G}$ (Pro1827Arg) polymorphism, related to an $\mathrm{E}$ surface low density of $\mathrm{CR} 1$ molecules, was significantly associated with IPF in comparison with controls (Chi-squared $=8.7496$, odds ratio $6.86,95 \%$ confidence interval 2.00-14.93). These findings are consistent with a novel, possible susceptibility gene factor for IPF. Moreover, it allows intriguing speculations about a susceptibility factor shared by two interstitial lung diseases, sarcoidosis and IPF.

I. Ferrarotti, M. Luisetti, R. Scabini, R. Trisolini, V. Poletti, M. Patelli, M. Novo, L. Lazzari Agli, M. Cuccia, M. Martinetti, E. Pozzi, M. Zorzetto

Clinica Malattie Apparato Respiratorio, IRCCS Policlinico San Matteo, Università di Pavia, Italy.

Zinc depletion causes a reduction in the ciliary beat frequency of human airway epithelial cells

Zinc $(\mathrm{Zn})$ is an important biometal, found in all cells throughout the body. It is potentially important in protecting the airway epithelium against oxidant stress caused by inflammation as well as in the repair of injured epithelium. In human airway epithelial cells (HAEC) there is an abundance of $\mathrm{Zn}$ in the apical cytoplasm, especially in and around the basal bodies. In chronic inflammation, this $\mathrm{Zn}$ may be depleted by shedding of the epithelial cells. The aim of this study was to investigate whether $\mathrm{Zn}$ has an important function in maintaining ciliary beat frequency $(\mathrm{CBF})$.

HAEC were obtained from patients undergoing bronchoscopy, by brushing the nasal and bronchial mucosa. The HAEC were then treated with N,N,N,N-tetrakis(2-pyridylmethyl)ethylene diamine (TPEN), a membrane-permeable $\mathrm{Zn}$ chelator, to functionally deplete labile intracellular $\mathrm{Zn}$. The $\mathrm{CBF}$ was measured at $33^{\circ} \mathrm{C}$ by a photometric technique using a microscope with heated stage and a photodiode.

$\mathrm{Zn}$ depletion significantly reduced the CBF of HAEC (table 1). This effect was small but present for both nasal and bronchial cells with $\mathrm{Zn}$ deficiency affecting bronchial cells to

Table 1. - Ciliary beat frequency in normal and zinc-depleted nasal and bronchial human airway epithelial cells

\begin{tabular}{lcc}
\hline Location & Zn-deficient & Control \\
\hline Nasal & $8.0 \pm 3.2^{* *}$ & $9.3 \pm 2.9$ \\
Bronchial & $6.8 \pm 3.0^{* *}$ & $8.8 \pm 3.2$ \\
Combined & $7.4 \pm 3.1^{* *}$ & $9.0 \pm 3.0$ \\
\hline
\end{tabular}

Data are presented as mean \pm SD. $\mathrm{n}$ are between $82-180$. **: $\mathrm{p}<0.01$ between control and N,N,N,N-tetrakis(2-pyridylmethyl)ethylene diamine-treated cells, t-test. a greater degree than nasal cells. Zn deficiency appears to reduce bronchial cell $\mathrm{CBF}$ to a greater degree $(22.7 \%)$ than nasal cells $(14.0 \%)$

These studies show that $\mathrm{CBF}$ is reduced by $\mathrm{Zn}$ depletion. Understanding the role of $\mathrm{Zn}$ in protecting HAEC may provide a new focus in measuring and manipulating $\mathrm{Zn}$ levels.

\section{Grosser, P. Zalewski, R. Ruffin}

Dept of Medicine, Basil Hetzel Institute, and University of Adelaide, The Queen Elizabeth Hospital, Woodville, Australia.

TNF- $\alpha$ is increased during respiratory syncytial virus infection and correlates with virus load

It remains an enigma why respiratory syncytial virus (RSV) infection may progress from sparse symptoms to severe bronchiolitis. Recently, researchers have targeted immune-mediated reactions. Much effort has been put into investigating murine models and in vitro production of cytokines both of which, however, have only limited use when applied to humans.

To test whether an in vivo predominance of the proinflammatory cytokine, tumour necrosis factor (TNF)- $\alpha$, in nasopharyngeal aspirations (NPA) from RSV-infected children, was related to severity of disease and the need for treatment, children aged $0-36$ months with acute respiratory tract symptoms were recruited during RSV epidemics in 2001-2002. NPAs were obtained in a highly standardised way. RSV was detected by direct immunofluorescence and scored according to virus load. TNF- $\alpha$ was analysed by ELISA (CLB).

Of 235 children (male:female 55:45\%), mean age 6.7 (range 0-36) months were recruited. Children with RSV were significantly longer hospitalised than children without RSV $(\mathrm{p}<0.00001$; fig. 1). TNF- $\alpha$ was significantly higher in RSV+ children than in RSV- ones $(p<0.05)$, the highest level was found in the most infected patients $(\mathrm{p}<0.05$; fig. 2). If children were febrile (rectal temperature $>38^{\circ} \mathrm{C}$ ), TNF- $\alpha$ was significantly higher $(\mathrm{p}<0.01)$. TNF- $\alpha$ did not correlate with oxygen saturation, respiratory rate, C-reactive protein, capillary $\mathrm{pH}$ or carbon dioxide tension.

In vivo secretion of $\mathrm{TNF}-\alpha$ in airway secretions from respiratory ill children predominates in $\mathrm{RSV}+$ children, especially in those with fever and high-level virus load. Characterisation of cytokine imbalances may pin-point infants at

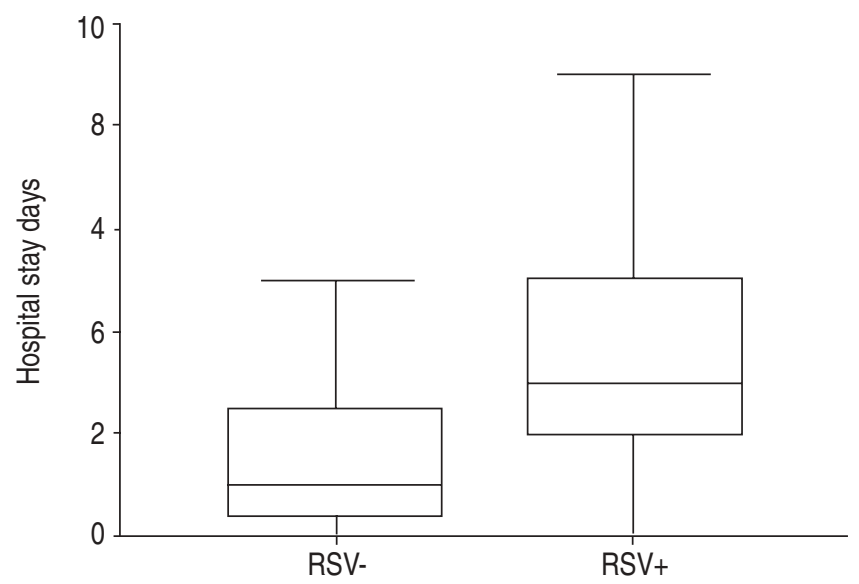

Fig. 1.-Respiratory syncytial virus (RSV) versus length of stay. RSV-: without RSV, $n=79$; RSV+: with RSV, $n=156$. 


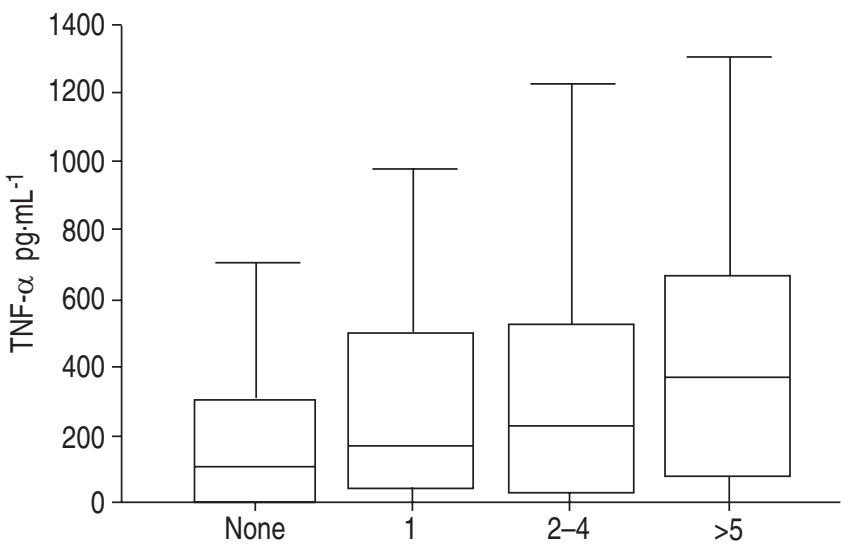

Fig. 2. - Tumour necrosis factor (TNF)- $\alpha$ versus viral load. $\mathrm{n}$ values from $32-79$.

risk of severe respiratory illness, and facilitate the development of new treatment modalities.

\section{Breindahl*,\#, K. Bendtzen" ${ }^{\#}$ K. Müller,}

*Dept of Paediatrics, Copenhagen University Hospital, Hilleroed, " Institute for Inflammation Research, and "Paediatric Clinic II, the National University Hospital (Rigshospitalet), Copenhagen, Denmark.

\section{Molecular mechanism of the damage of the alveolar- capillary barrier in response to inflammatory stimuli}

The damage of the alveolar-capillary barrier plays an important role in a large number of chronic lung diseases, such as bronchial asthma. In this process, inflammatory mediators may have a significant role. The aim of this study was to elucidate the molecular mechanisms of the barrier damage elicited by inflammation, which has been shown to be a key element in the pathogenesis of bronchial asthma. The interepithelial junctional proteins (occludin, cadherin, catenins), which form the molecular basis of the alveolar-capillary barrier, have been investigated by using dexamethasone. Reduction of the possible barrier damage caused by inflammatory cytokines was attempted.

Experiments were performed on the A549 alveolar epithelial cell line, which has been largely used as a model system. The cells were treated with different concentrations of tumour necrosis factor (TNF)- $\alpha$. The expression and localisation of junctional proteins have been studied by Western blot analysis and immunofluorescence, respectively. The interaction of junctional proteins was investigated by coimmunoprecipitation. The possible activation of proteolytic mechanisms was studied by zymography.

Treatment with TNF- $\alpha$ of these cells caused no significant change in the expression of occludin, a transmembrane component of the tight junction, however, immunofluorescent studies showed a redistribution of this protein. Moreover, coimmunoprecipitation studies revealed a disruption of the cadherin-catenin complex that could lead to damage of the barrier. TNF- $\alpha$ was found to induce a strong activation of the $72 \mathrm{kD}$ matrix metalloproteinase- 2 that is released in the culture medium. This effect could be blocked by dexamethasone.

These results indicate that the inflammatory processes of the airways induce an increased proteolytic activity of the epithelial cells, and by disrupting the junctional complex lead to the damage of the alveolar-capillary barrier, which is accompanied by increased permeability and antigen invasion.

H. Szabo*, H. Bauer" ${ }^{\#}$, Z. Novak ${ }^{\top}$, E. Szatmari ${ }^{\oplus}$, I.A. Krizbai ${ }^{\#}$ *Institute for Molecular Biology, Salzburg, and ${ }^{\#}$ Dept of Paediatrics, University of Szeged, Faculty of Medicine, Albert Szent-Györgyi Medical and Pharmaceutical Centre, Austria. ${ }^{\top}$ Hungarian Academy of Sciences, Biological Research Centre, Szeged, Hungary.

\section{Induction of apoptosis in asthmatic epithelial cells in response to decreased $S O D$ activity}

Superoxide dismutase (SOD) is an essential enzyme that eliminates superoxide and protects cells from damaging effects of oxidant stress. Asthma is associated with an increase in superoxide production, and the authors have previously reported that SOD activity is decreased in asthmatic lungs. It was hypothesised that increased superoxide production and low SOD activity in asthmatic lung contribute to epithelial cell injury, a common manifestation of asthma, in part through activation of apoptotic pathways. Endobronchial biopsies of asthmatic individuals $(\mathrm{n}=4)$ had increased TUNEL-positive cells $(28 \pm 3 \%)$ versus controls $(0.4 \pm 0.2 \%, n=5 ; p<0.05)$. Furthermore, activation of caspase 3 and 9 and poly (adenosine diphosphate)-ribose polymerase (PARP) was noted in asthmatic bronchial epithelial cells. To test whether loss of SOD activation mediates apoptosis, the effect of 2-methoxyoestradiol, a SOD inhibitor, was studied on human airway epithelial cells. Targeting SOD activity led to cleavage/activation of caspase 3 and 9 and PARP, concomitant with increased oxidative stress as shown by increased numbers of nitrated protein. Upregulation of BAX and lack of caspase 8 cleavage suggests the involvement of a mitochondria-dependent pathway of apoptosis. These findings indicate that the loss of SOD along with increased oxidative and nitrosative stress in asthma causes apoptosis of epithelial cells, manifested as in epithelial shedding in asthma.

S.A.A. Comhair, W. Xu, H.M. Markgraaff, S.C. Erzurum The Cleveland Clinic Foundation, Lerner Research Institute, Cleveland, OH, USA.

IL-4 concentrations in the lungs of infants with severe respiratory syncytial virus bronchiolitis decline over the course of the illness

Bronchiolitis caused by respiratory syncytial virus (RSV) infection is an important cause of lung disease in infants and increasing evidence suggests that it is immunologically mediated. The authors have shown previously that infants with severe RSV bronchiolitis demonstrate cytokine expression skewed to either type-1 or type- 2 responses, but it was unclear whether these responses changed during recovery from the illness. The aim of this study was to characterise the T-helper cell response in infants ventilated with RSV bronchiolitis throughout the course of the illness.

Nonbronchoscopic bronchoalveolar lavage (BAL) was performed on infants ventilated for RSV bronchiolitis over the first 5 days following intubation. BAL samples were analysed for interleukin (IL)-4, interferon (IFN)- $\gamma$ and IL-4 receptor mRNA expression using RNase protection assays. BAL IL-4 and IFN- $\gamma$ protein concentration was quantified using commercially available ELISAs. 


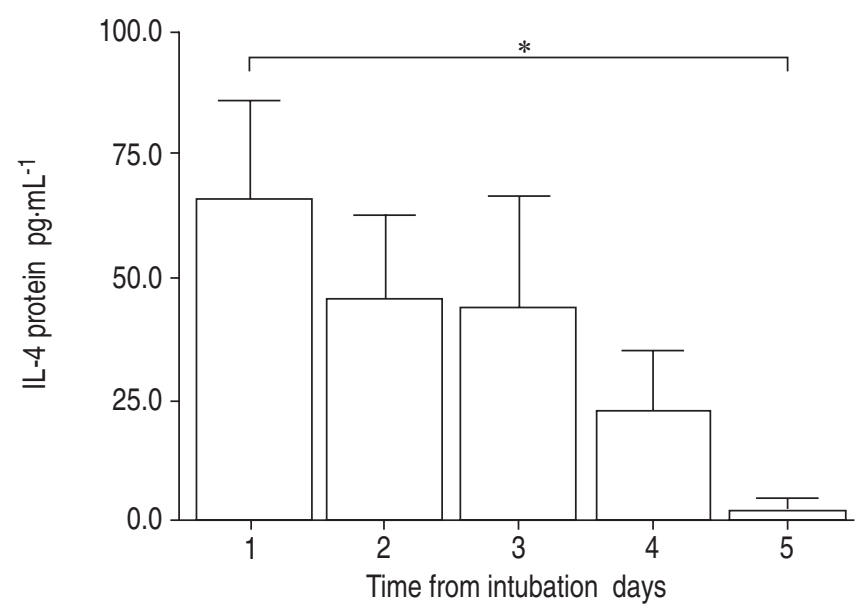

Fig. 1. - Interleukin (IL)-4 protein in the first 5 days of ventilation. *: $\mathrm{p}<0.05$.

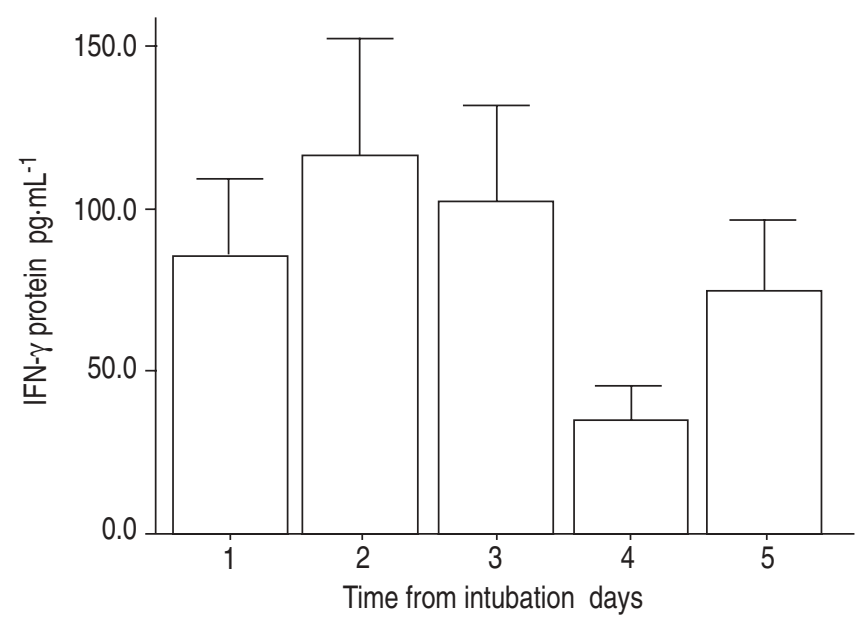

Fig. 2. - Interferon (IFN)- $\gamma$ protein in the first 5 days of ventilation.

BAL samples $(n=143)$ were collected from 47 infants (median age 11 weeks, median ventilation time $136 \mathrm{~h}$ ). The cellular composition of BAL predominantly comprised neutrophils (83\%). IL-4 and IFN- $\gamma$ mRNA expression was not detected in BAL from any infant. IL-4 protein was detected in 81 of 143 and IFN- $\gamma$ protein in 92 of 143 BAL samples. IL-4 showed a sharp decline over the first 5 days of ventilation (fig. 1). In contrast, IFN- $\gamma$ protein stayed relatively constant over this period (fig. 2). IL-4 receptor mRNA expression was detected in 26 of 30 infants.

In these infants with severe RSV bronchiolitis, the presence of IFN- $\gamma$ and IL- 4 protein in the BAL in the absence of mRNA suggests that production of these cytokines is occurring within the lung parenchyma. The decline in IL-4 concentration during the period of ventilation, suggests that this may contribute to recovery from RSV disease.

P.S. McNamara, B.F. Flanagan, C.A. Hart, R.L. Smyth University of Liverpool, Liverpool, UK.

Granulocyte apoptosis in the airways of normal volunteers and COPD patients

Chronic obstructive pulmonary disease (COPD) is a neutrophilic airway inflammatory disorder. Neutrophils die constitutively by undergoing apoptosis. This mechanism is poorly understood in vivo. It was postulated that granulocyte apoptosis is affected in the airways of patients with COPD and inflammatory mediators may play a role. This study examined bronchoalveolar lavage (BAL) and induced sputum (IS) from normal volunteers and patients with COPD.

Ten normal volunteers (mean \pm SEM age $56 \pm 4$ yrs, FEV1 $92.6 \pm 2.1 \%$ ) and 10 patients with COPD (age $65 \pm 2$ yrs, FEV1 $46.8 \pm 4 \%$ ) underwent BAL followed at least 1 week later by IS. BAL and IS were processed using standard methods. Cell cytospins were prepared and apoptotic neutrophils (NA \%) were assessed by morphology. Soluble interleukin (IL)-8, IL10, leukotriene (LT) $\mathrm{B}_{4}$ and neutrophil elastase (NE) were assayed by immunoassay. Granulocytes were assessed by flow cytometry using annexin V (AV) and propidium iodide (PI) and categorised as positive $(+)$ or negative $(-)$ for each marker.

In COPD BAL, a higher percentage of granulocytes are in the fully active form (AV-PI-) compared with normal BAL $(69.5 \%(65.3-83.8)$ versus $32.2 \%(20.0-45.7) ; \mathrm{p}<0.05)$ and $\mathrm{a}$ lesser percentage of granulocytes are in the late necrotic phase (AV-PI+) compared with normal BAL (9.9\% (3.6-23.4) versus $28.1 \%(19.5-39.5) ; \mathrm{p}<0.05)$. There is a similar (nonsignificant) trend in COPD IS. In COPD IS, lymphocyte percentage correlates negatively with AV-PI- $(r=-0.7, p=0.04)$. In COPD $\mathrm{BAL}$, there is a positive correlation with AV-PI- $(\mathrm{r}=0.72$, $\mathrm{p}=0.02)$. $\mathrm{LTB}_{4}$ also correlates with COPD BAL AV-PI$(\mathrm{r}=0.74, \mathrm{p}=0.01)$.

There is evidence of abnormal granulocyte apoptosis in BAL in COPD. Lymphocytes and $\mathrm{LTB}_{4}$ may have a role. Different effects are noted in IS compared with BAL, supporting the concept of compartmentalisation of the airways.

\section{M.G. Kelly, V. Brown, J.S. Elborn, M. Ennis}

Respiratory Research Group, Centre for Inflammation, Infection and Repair, Queen's University, Belfast, UK.

Cigarette smoke-induced inflammatory changes as a mechanism of pulmonary vascular impairment in COPD

Structural abnormalities and endothelial dysfunction in pulmonary arteries can be observed in both smokers with normal lung function and nonhypoxaemic patients with mild chronic obstructive pulmonary disease (COPD). These observations suggest that mechanisms other than hypoxaemia could be at the origin of pulmonary hypertension in COPD. The aetiopathogenic mechanisms of these early vascular abnormalities may be related to an inflammatory process promoted by cigarette smoke components.

Accordingly, the number of CD8+ cells infiltrating the adventitia, the endothelium-dependent relaxing response, and the expression of endothelial nitric oxide (eNOS) in pulmonary arteries (PA) of smokers were counted. Patients $(n=29)$ who underwent lung resection were divided according to their smoking habit. To rule out chronic lung disease or hypoxaemia as potential causes of pulmonary vascular changes, patients with an arterial oxygen tension of $<75 \mathrm{mmHg}$ and, those who had moderate-to-severe airflow obstruction (FEV1 $<65 \%$ predicted) were excluded.

Lung paraffin-embedded tissue sections were immunostained with antibodies for CD4 and CD8 T-cells and endothelial nitric oxide synthase (eNOS). Positive cells were counted in the adventitia of $10 \mathrm{PA}$ and reported as cells $\cdot \mathrm{mm}^{-2}$. Positive arteries for eNOS were counted and expressed as per cent of the total number of arteries. Maximal relaxation of PA was 
Table 1. - Pulmonary artery abnormalities in smokers

\begin{tabular}{lccc}
\hline & Nonsmokers & Smokers & p-value \\
\hline Maximal relaxation to ADP \% & $82 \pm 14$ & $73 \pm 14$ & 0.009 \\
eNOS \% total arteries & $87 \pm 9$ & $64 \pm 19$ & 0.007 \\
Intimal area \% total area & $21 \pm 5$ & $29 \pm 6$ & 0.002 \\
CD8+ cells $\cdot \mathrm{mm}^{-2}$ & $82 \pm 32$ & $210 \pm 112$ & 0.007 \\
CD4+ cells $\cdot \mathrm{mm}^{-2}$ & $175 \pm 65$ & $185 \pm 122$ & 0.836 \\
\hline
\end{tabular}

ADP: adenosine diphosphate; eNOS: endothelial nitric oxide synthase. p-value from unpaired t-test.

evaluated in vitro using adenosine diphosphate (ADP), an endothelium-dependent vasodilator (table 1).

These results show that smokers had a lower number of arteries with positive immunoreactivity for eNOS and greater inflammatory infiltrate, compared with nonsmokers. The number of CD8+ cells was inversely correlated with the immunoreactivity to eNOS $(\mathrm{r}=-0.52, \mathrm{p}<0.01)$ and with the maximal relaxation to ADP $(r=-0.39, p<0.05)$. It is concluded that the reduction of eNOS expression in smokers is associated with greater inflammatory infiltrate in the arterial wall, largely constituted by CD8+ T-lymphocytes, suggesting that pulmonary vascular impairment in COPD may be initiated by cigarette smoking.

\section{V.I. Peinado, J.A. Barberà}

Servei de Pneumologia, Hospital Clínic, Universitat de Barcelona, Spain.

\section{A functional $C O X-2$ promoter variant, $-765 G>C$, associates with poorer outcome in sarcoidosis}

In normal lung fibroblasts upregulation of cyclooxygenase (COX)-2 results in the synthesis of antifibrotic prostaglandin $(\mathrm{PG}) \mathrm{E}_{2}$. Patients with idiopathic pulmonary fibrosis (IPF) have low levels of lung $\mathrm{PGE}_{2}$ despite the presence of mediators capable of stimulating its synthesis. This is thought to be due to a reduced capacity to upregulate COX-2. This phenomenon may in part be due to sequence variants present in the regulatory regions of the gene.

The authors have previously reported a novel promoter variant, $-765 \mathrm{G}>\mathrm{C}$, that is carried by $25 \%$ of a UK healthy population. The $-765 \mathrm{C}$ allele decreases COX-2 promoter activity by $30 \%$ in reporter gene assays in human lung fibroblasts, under both basal and stimulated conditions. It was hypothesised that the $-765 \mathrm{C}$ allele would associate with lung fibrosis. The $-765 \mathrm{G}>\mathrm{C}$ variant was genotyped in healthy UK subjects, IPF and sarcoidosis patients (table 1). There

Table 1.-Genotype distribution and rare allele frequency (RAF) of $-765 \mathrm{G}>\mathrm{C}$ in UK healthy subjects, idiopathic pulmonary fibrosis (IPF) and sarcoidosis patients

\begin{tabular}{lccc}
\hline & Healthy subjects & IPF & Sarcoidosis \\
\hline $\mathrm{n}$ & 454 & 78 & 94 \\
$\mathrm{RAF} \%$ & 0.13 & 0.14 & 0.19 \\
$95 \% \mathrm{CI}$ & $0.11-0.16$ & $0.08-0.19$ & $0.13-0.24$ \\
$\mathrm{p}-$ value & & 0.99 & 0.16 \\
GD \% & $339 \pm 74.7$ & $59 \pm 75.6$ & $62 \pm 66.0$ \\
& $109 \pm 24.0$ & $17 \pm 21.8$ & $29 \pm 30.8$ \\
& $6 \pm 1.3$ & $2 \pm 2.6$ & $3 \pm 3.2$ \\
p-value & & 0.66 & 0.14 \\
\hline
\end{tabular}

CI: confidence interval; GD: genotype distribution. was no difference in allele or genotype frequencies overall between the healthy subjects and either disease group.

However, within the sarcoidosis group carriage of the rare $-765 \mathrm{C}$ allele was associated with the risk of poorer outcome (odds ratio (OR) 2.4, 95\% confidence interval (CI) 1.01-5.92; $\mathrm{p}=0.04$ ). The genotype distribution of $-765 \mathrm{G}>\mathrm{C}$ in sarcoidosis patients with nonpersistent disease $2 \mathrm{yrs}$ from diagnosis appeared similar to that of the healthy subjects. When patients with progressive disease were compared with the healthy subjects, carriage of the rare allele gave an OR of 2.6, a $95 \%$ CI of $1.29-5.31$, and $\mathrm{p}=0.006$. In conclusion, these results suggest that the $-765 \mathrm{G}>\mathrm{C}$ variant predicts poorer outcome in sarcoidosis.

\section{Hill}

Centre for Respiratory Research, University College, London, UK.

Stimulation of lung epithelial wound repair by human neutrophil defensins

Human airways are frequently exposed to potentially harmful agents that cause tissue injury. Upon such injury, a repair process is initiated that comprises cell migration, proliferation and differentiation. The authors have previously shown that human neutrophil defensins (HNP)1-3, small cationic antimicrobial peptides, induce lung epithelial cell proliferation. Here, the effect of HNP1-3 on airway epithelial wound closure, the role of cell migration and proliferation in this process, and the signalling pathways involved were investigated. Using mechanically wounded NCI-H292 airway epithelial cell monolayers, it was shown that HNP1-3 induced a dose- and time-dependent increase of wound closure. HNP1-3 also significantly increased cell migration as determined in modified Boyden chamber experiments. Furthermore, bromodeoxyuridine-incorporation experiments in wounded NCI-H292 cell monolayers showed that HNP1-3 caused a localised increase in cell proliferation within the wound area in the time period $24-48 \mathrm{~h}$ after stimulation, but not in the first $24 \mathrm{~h}$. The effects of HNP1-3 on wound closure were blocked by specific inhibitors of the mitogen-activated protein kinase (MAPK) kinase MEK (U0126 and PD98059), epidermal growth factor (EGF) receptor tyrosine kinase (AG1478), phosphatidylinositol 3-kinase (LY294002) and Src (PP1). Finally, HNP1-3 induced activation of the MAPKs extracellular signal-related kinase $1 / 2$, that were inhibited by U0126 and PD98059. These results indicate that neutrophil defensins increase epithelial wound repair, which involves migration and proliferation. Neutrophil defensininduced wound repair appears to require EGF receptor activation and downstream signalling pathways.

J. Aarbiou, R.M. Verhoosel, S. van Wetering, K.F. Rabe, P.S. Hiemstra

Dept of Pulmonology, Leiden University Medical Centre, Leiden, The Netherlands.

\section{SP-C gene mutations and lung fibrosis: a novel form of conformational disease}

Human surfactant protein (hSP)-C is synthesised as a 197 amino acid proprotein and proteolytically processed to the $3.7 \mathrm{kD}$ alveolar form ("mature SP-C"). Recently a number of mutations in the SP-C proprotein have been associated with 
an absence of mature SP-C and the development of chronic lung disease in humans.

It was hypothesised that mutations in the SP-C gene, associated with chronic lung disease, lead to disruption of intracellular trafficking of pro-SP-C. Heterologous fusion proteins consisting of epidermal growth factor (EGF) attached to the $\mathrm{NH}_{2}$ terminus of wildtype human SP-C were compared with fusions containing one of several novel mutations identified in children with chronic lung disease. The fate of the proteins expressed in A549 cells after transfection with the constructs was investigated. Whereas the wildtype protein fused to EGFP was expressed in a punctate pattern within CD-63-positive, EEA1-negative vesicles, the expression pattern of the mutated proteins differed greatly. The previously published ${ }^{\Delta}$ Exon 4 mutation in the $\mathrm{COOH}$ propeptide $\left(\mathrm{hSP}-\mathrm{C}^{\Delta \text { Exon4}}\right)$ formed ubiquitinated perinuclear aggregates. Aggresome formation was also observed following transfection of mutant SP-C lacking two conserved Cys residues encoded by Exon $4\left(\mathrm{EGFP} / \mathrm{hSP}-\mathrm{C}^{\mathrm{C} 120 / 121 \mathrm{G}}\right)$. The expressed protein of a mutation (E66K) found in a newborn with nonspecific interstitial pneumonia and alveolar proteinosis was located at the plasma membrane and in small EEA1positive cytoplasmic vesicles with a variable degree of aggregation.

From these and other experiments it is concluded that mutations in the coding regions of the SP-C gene can lead to intracellular trafficking defects of the SP-C protein. The toxic effects of these defects lead to clinically relevant lung pathology. Depending on the location of the mutation in the SP-C protein-coding gene sequence, different patterns of transport defects and different lung pathology occur.

\section{P.A. Stevens, H. Witt, M.F. Beers}

University Children's Hospital Charité, Humboldt University, Berlin, Germany. Pulmonary and Critical Care Division, Dept of Medicine, University of Pennsylvania School of Medicine, Philadelphia, PA, USA. 